\title{
5. »BEUTE UND SCHMUGGEL» ABDELKRIM UND DER NACHSCHUB FÜR DAS RIF
}

\subsection{Der Nachschub aus der spanischen Zone Marokkos}

Für seinen Kampf gegen Spanien und Frankreich benötigte Abdelkrim modernes Kriegsgerät, das er zum einen seinen Gegnern abnehmen und zum anderen über vielerlei Kontakte einschmuggeln ließ. Wichtig war ebenso der ständige Nachschub an Lebensmitteln für die Rifbevölkerung, deren Ernten für die Selbstversorgung nicht immer ausreichten. Abdelkrims Hoffnung, den spanisch-französischen Protektoratstruppen eine modern ausgerüstete Armee entgegenzustellen, reichte bis zum Traum von einer eigenen Luftwaffe. Die Rifsoldaten sollten mit geeignetem Material ausgestattet sein, um den Gegnern trotzen zu können. Über Jahre hinweg versuchte Abdelkrim trotz aller Blockademaßnahmen, Nachschubmaterial aller Art insbesondere über FranzösischMarokko, Algerien, Tanger und Gibraltar ins Rif zu schmuggeln. Waffen, technische Geräte, Lebensmittel und tägliche Gebrauchsgüter fanden mit Hilfe von Karawanen oder über das Mittelmeer ihren Weg zu den Rifkabylen.

Die Archive bieten über den Umfang des Schleichhandels ins Rif nur wenig Zahlenmaterial. Insofern sind genauere Schätzungen über die Menge des geschmuggelten Kriegsgerätes praktisch nicht möglich. Realisierbar ist aber eine Analyse der Methoden und der Wege sowie die Identifizierung zahlreicher 'Hintermänner<. Die Grundlage bilden Presse- und Augenzeugenberichte sowie deutsche, französische und britische Quellen der jeweiligen Außenministerien, die durch spanische Konsularberichte ergänzt werden. Die Grenze zwischen Wahrheit, Gerüchten, Phantasien, Vermutungen und pauschalen Verdächtigungen ist zum Teil schwer zu ziehen. Es finden sich jedoch auch eine ganze Reihe detaillierter und glaubwürdiger Berichte offizieller Stellen, die durch Aussagen der Augenzeugen vor Ort sehr gut ergänzt werden.

Die spanische Historikerin Susana Sueiro Seoane hat 1995 die bisher einzige spezielle Analyse zum Waffenschmuggel während des Rifkrieges vorgelegt. In ihrer Studie fehlen die Aussagen sämtlicher Zeitzeugen, die im Rif gewesen waren und über Nachschublieferungen berichtet haben. Transporte an Lebensmitteln, technischem Gerät oder etwa Medikamenten, die ebenso ins Rif eingeschmuggelt werden mußten, werden ausgeklammert. Ihr Ergebnis, die Anzahl des gelieferten Waffenmaterials sei unbedeutend gewesen, wird sich als nicht haltbar erweisen ${ }^{1}$.

' SUeIro SeOANE, Contrabando, S. 266; DIES., Spanish Colonialism during Primo de Rive- 
Die Rifkabylen waren (und sind) aufgrund der Kargheit und Armut ihrer Heimat erfahrene Schmuggler. In den 1830er-1840er Jahren entsandte der Sultan von Marokko vergeblich mehrere Militärexpeditionen ins Rif, um den ausufernden Schmuggelhandel zu unterbinden. Nach 1860 gewann das geheime Geschäft mit modernen Waffen aus Gibraltar und Malaga noch an Bedeutung $^{2}$. Die Rifküste war hierfür besonders deswegen geeignet, weil der Sultan hier keinerlei Einfluß ausüben konnte. Vom Rif aus wurden Waffen, die auch aus Deutschland - speziell Hamburg - stammten, bis zur Sahara weitertransportiert ${ }^{3}$. Ende der 1880er Jahre gab es ein Überangebot an Gewehren, das die Schmuggelpreise stark fallen lie $\beta^{4}$. Auch die Errichtung des französisch-spanischen Protektorats in Marokko vermochte den Handel mit Waffen ins Rif nicht zu unterbinden'.

Kurz vor der Schlacht von Annual im Juli 1921 verfügten die Rifkämpfer allerdings über derart wenig Munition, daß von einem Offizier des spanischen Forts in der Bucht von Alhucemas Nachschub an Patronen gekauft werden mußte ${ }^{6}$. Daß schlecht bezahlte und unterernährte spanische Soldaten - auch Offiziere - Waffen und Munition an Einheimische verkauften, war nichts Ungewöhnliches ${ }^{7}$.

Die meisten Männer im Rif besaßen veraltete Gewehre. Neuere Waffen stammten aus der Zeit des Ersten Weltkrieges, als Abdelkrim und sein Vater den Schmuggel zur Rifküste organisiert hatten, um die deutsche „Marokko-

ra's Dictatorship, in: Raanan REN (Hg.), Spain and the Mediterranean since 1898, London 1999, S. 48-64, S. 61, Anm. 13. Die spanische Historikerin bält die spanischen Militäraktionen während des Rifkrieges allen Ernstes noch heute für >Pazifizierungsmaßnahmen` [Ibid. S. 54, S. 63, Anm. 33].

${ }^{2}$ AYACHE, Société rifaine, S. 360-363; Moulèras, Le Maroc, Bd. 1, S. 114; PENNELL, Morocco since 1830, S. 47; DERS., The Discovery, S. 227. Zu den Rifpiraten des 19. Jahrhunderts: DERS., Dealing with Pirates. British, French and Moroccans 1834-56, in: Journal of Imperial and Commonwealth Studies 22 (1994) S. 54-83; DERS., The Geography of Piracy. Northern Morocco in the Mid-Nineteenth Century, in: Journal of Historical Geography 20 (1994) S. 272-282; Otto C. ARTBAUER, Die Rifpiraten und ihre Heimat. Erste Kunde aus verschlossener Welt, Stuttgart 1911.

${ }^{3}$ Ross E. DunN, Bu Himara's European Connexion. The Commercial Relations of a Moroccan Warlord, in: Journal of African History 21 (1980) S. 235-253, S. 242; NiMSCHOWSKI, Das Eindringen, S. 118; WILlaMSON, Germany and Morocco, S. 122.

4 PENNELl, Morocco since 1830, S. 102f.; MİGE, Le Maroc, Bd. 4, S. 106.

${ }^{5}$ MONTORO ObRERo, Tráfico de armas, S. 245; SÁNCHEZ PÉREZ, Abdelkrim, S. 137.

${ }^{6}$ FurNEAUX, Abdel Krim, S. 58.

${ }^{7}$ ÁlvareZ, The Betrothed of Death 1995, S. 21; CADN Maroc DAI 198: Bericht »Renseignements recueillis près des divers personnages de l'entourage d'Abdelkrim« o.D. [Mitte 1926] mit Bezug auf Aussagen von Abdelkrims wschwarzem Doktor« Mahboub; Robert GORDON-CANNING, The Riff, in: Foreign Affairs 6 (1924-1925) S. 209-211, S. 210; PROFO 371, 9470, 44, 98: WO an FO, 17.10.1923 mit einem beigefügten Bericht von Mrs. McGrath (d.i. Rosita Forbes), 27.9.1923; PRO-FO 371, 9470, 44, 51: Minute, 19.9.1923. 
Aktion « zu unterstützen ${ }^{8}$. Für seine ersten Kämpfe gegen die Spanier soll Abdelkrim ein kleines, von den Deutschen zu Weltkriegstagen in der Bucht von Alhucemas vergrabenes Waffendepot genutzt haben ${ }^{9}$. Die siegreichen Kämpfe der Rifkabylen im Sommer 1921 insbesondere in Annual brachten reichlich Kriegsbeute ein - ungefähr 11000 Gewehre, 3000 Karabiner, 1000 Musketen, 60 Maschinengewehre, 2000 Pferde, 1500 Mulis, 100 Kanonen und Massen an Munition ${ }^{10}$. Abdelkrim erinnerte sich: "Spanien lieferte uns über Nacht alles, was uns an Ausrüstung fehlte, um einen großen Krieg zu führen ${ }^{11}$. Er befahl seinen Kämpfern zusätzlich, bei jeder Gelegenheit feindliche Waffen und Munition einzusammeln. Je höher die Beute eines Kämpfers war, umso mehr stieg sein Ansehen. Für ihre Abgabe zahlte Abdelkrim, um die Motivation zu steigern, Geldbeträge. Caïd Haddou ben Hammou organisierte die Überführung des erbeuteten Kriegsmaterials ins Rif ${ }^{2}$.

»Beute und Schmuggel ${ }^{13}$ lieferten den Rifkämpfern von nun an permanenten Zufluß an Material. Die spanische Armee blieb Abdelkrim zufolge bis 1925 eine Art "natürliche Nachschubquelle ${ }^{14}$ für die Rifkabylen. Marokkanische Soldaten der spanischen Armee verkauften Waffen an Tangerer Geschäftsleute, die sie direkt an Agenten Abdelkrims weiterleiteten ${ }^{15}$. Im Juli 1925 wurden zwei Spanier in Tetuan wegen Waffenhandels mit den Rifkabylen verhaftet. Ihnen drohte die Exekution. Doch einer schaffte es, eine Liste mit den Namen der Offiziere, in deren Interesse der Waffenverkauf durchgeführt worden war, aus dem Gefangnis zu schmuggeln. Als seine Familie mit der Publikation der Liste drohte, wurde die Exekution ausgesetzt ${ }^{16}$. Auch der Rückzug der spanischen Truppen aus Chichaouen führte Ende 1924 dazu, daß sehr viel Kriegsmaterial an die Riftruppen überging ${ }^{17}$.

Viele Schmuggelpfade führten aus dem spanisch besetzten Gebiet Marokkos ins Rif. Ein Zentrum war Melilla. Der jüdische Händler Moises Morely Levy und der Hotelier David Cohen versorgten Abdelkrim mit Waffen und gewähr-

${ }^{8}$ BURKe, Moroccan Resistance, S. 451; LADREIT DE LACHARRIĖRE, Le rêve, S. 100; SHINAR, Abd al-Qadir, S. 161, Anm. 99; WOOLMAN, Rebels in the Rif, S. 77; SÁNCHEZ PÉREZ, Abdelkrim, S. 138; PAYNE, Politics, S. 103; HARRIS, France, S. 66. Siehe zur »MarokkoAktion « Kapitel 2, S. 26, S. 33-36.

${ }^{9}$ CADN Madrid C273: MAE an Ambassade de Madrid, 22.5.1922.

${ }^{10}$ LA PORTE, La atracción del imán, S. 113.

$"$ ABDELKRIM, Memoiren, S. 71.

${ }^{12}$ WoOlman, Rebels in the Rif, S. 153; PenNell, A Country, S. 100f.; BevaN, Spain and Morocco II, 23.10.1923.

${ }^{13}$ ABDELKRIM, Memoiren, S. 100.

${ }^{14}$ Polk, The Education, S. 25.

${ }^{15}$ WOOLMAN, Rebels in the Rif, S. 155.

${ }^{16}$ TNLA, BNS, 1, Williams: Walter Harris an Harold Williams, 25.7.1925.

${ }^{17}$ CADN Maroc DAI 192: Tabor de police $\mathrm{N}^{\circ} 1$ Tanger an DAI Rabat, 11.7.1925; FRAUENHOLZ, Der spanische Krieg, S. 103; MOHR, Frankreich, S. 308. 
ten ihm Kredite. Cohens Komplize war der Händler Ibrahim ${ }^{18}$. Der Österreicher Lussnig, der Besitzer zweier Hotels in Almeria und Melilla, stand im Verdacht, mit Waffen zu handeln. Er machte dem aus Belgien stammenden Spanier Maurice Heldenbergh den Vorschlag, ihn für den Transport von Munition ins Rif zu beschäftigen ${ }^{19}$. Aus Melilla besorgten sich die Rifkabylen Zucker, Tee, Seife, Kerzen und Stoffe ${ }^{20}$. Der dort lebende Deutsche Otto Bohrer wurde, als er im April 1926 zu den Rifkabylen durchstoßen wollte, von spanischen Truppen bei Tizroutine verhaftet ${ }^{21}$.

Eine in fünf Gruppen aufgeteilte und von einem Italiener angeführte Karawane mit 50 Tieren verließ Larache im Dezember 1925 in Richtung Rif - kein Einzelfall, wie der französische Journalist Pierre Loze anführte ${ }^{22}$. Französische Stellen beschuldigten den Reeder Juan March von der Insel Mallorca - den sogenannten »König der Schmuggler « ${ }^{23}$-, das Rif mit Lebensmitteln und mit Waffen zu beliefern. An Dienstagen und Samstagen landeten die ansonsten für Tabakschmuggel verwendeten Schiffe in der Bucht von Alhucemas, um für die Entladung das Signal Rotes Feuer - Grünes Feuer - Rotes Feuer zu geben. Nur die herzlichen Beziehungen zum Diktator Primo de Rivera bewahrten March vor einer Verfolgung ${ }^{24}$. Aus Spanien selbst fanden ansonsten nur wenig Waffen den Weg ins Rif $^{25}$.

Abdelkrim kannte keine Finanzierungsprobleme. Im März 1921 hatte er von der Bergbaugesellschaft Sociedad minera Setolazar 400000 Peseten erhalten, die er in Waffenkäufe investierte ${ }^{26}$. Abdelkrim zapfte auch örtliche religiöse Spendenfonds an. Dies brachte islamische Bruderschaften im Rif gegen ihn auf. Weitere Finanzquellen waren Steuern und geschätzte Geldbeträge bis zu

${ }^{18}$ FLEMING, Primo de Rivera and Abd-el-Krim, S. 221f.; ADMAE Maroc 220, 92: EMA, $2^{e}$ bureau, Bericht $》$ Contrebande d'armes au Maroc«, 15.6.1925.

${ }^{19}$ CADN Maroc DAI 194: Bericht »Note au sujet du ravitaillement en armes et munitions du Rif par mer«, 30.5.1925; ADMAE Maroc 220, 33: Consul général de Sevilla an MAE, 28.5.1925; BOUTBOUQALT, La Guerre du Rif, S. 57.

${ }^{20}$ CADN Tanger C40: Tabor de police $\mathrm{N}^{\circ} 1$, Bericht $»$ Renseignements donnés par Abdelkrim El Hadj El Bokkoyi«, 5.3.1926.

${ }^{21}$ CADN Tanger C40: Tabor de police $N^{\circ} 1$, Renseignements, 28.4.1926.

${ }^{22}$ Pierre LOZE, Tanger, repaire de bandits, citadelle des contrebandiers, in: Petit Journal, 6.4.1926. Loze bezieht sich auf den Augenzeugenbericht eines französischen Journalisten, der die Karawane begleitete.

${ }^{23}$ PRO-FO 371, 10583,783 , 4: Minute, 22.5.1924.

${ }^{24}$ ADMAE Maroc 220, 71: Bericht „Vivres et munitions envoyées aux Riffains «, 4.6.1925; CADN Tanger C39: Marine au Maroc, Commandant, Bericht "Agissements britanniques au Riffe, 17.6.1925; AN F7, 14679: MI, Direction des affaires politiques et commerciales, Bericht »Bâtiments suspects de contrebande pour le Maroc«, 6.8.1925; SHAT 3H102: EMA, $2^{\mathrm{e}}$ bureau, Renseignement, 21.7.1925; Bernardo DIAZ NOSTY, La irresistible ascensión de Juan March. Notas previas para una investigación biográfia, Madrid 1977, S. 62.

${ }^{25}$ ADMAE Maroc 220, 115: Bericht »Résultats d'une enquête sur la contrebande des armes pour le Riff, par les ports du sud de l'Espagne«, 21.6.1925.

${ }^{26}$ LA PORTE, La atracción del imán, S. 103. 
16 Millionen Peseten, die Abdelkrim seinem Widersacher im Jebala-Gebiet, Ahmed el Risouni, Anfang 1925 abnehmen konnte. Hinzu kamen Geldbußen für Kabylen, die in Gegnerschaft zu Abdelkrim standen - wie die Ghomara (30 000 Peseten 1923), die Akhmas (20 000 Peseten 1924) und die Beni Zeroual (50 000 Peseten 1925). Für 1924 betrugen die Gesamteinnahmen der "Rif-Republik» etwa sechs Millionen Peseten ${ }^{27}$.

Die Gelder flossen also reichlich aus dem Rif selbst. Sie kamen jedoch auch von außerhalb, insbesondere aus Spanien. Der britische Botschafter Esme Howard schätzte, daß sich Abdelkrim für jeden Konvoi, der die Versorgung der spanischen Gefangenen von Annual aus dem Jahre 1921 gewährleistete, rund 15 000-50 000 Peseten von Spanien zahlen ließ. Das Geld nutzte er zum Kauf von Waffen und Munition ${ }^{28}$. Für die Freilassung der Gefangenen Anfang 1923 ließ sich Abdelkrim über vier Millionen Peseten auszahlen. Der Großteil hiervon wurde für die Aufrüstung ausgegeben. Verbündete Scheichs warnten die Spanier davor, daß Abdelkrim das Geld gegen sie verwenden würde ${ }^{29}$.

Nicht anders verhielt es sich, als die spanischen Truppen sich Ende 1924 zur Primo-de-Rivera-Linie zurückziehen und Posten um Posten aufgeben mußten. Viele Kommandanten kauften sich und ihre Soldaten für den ungehinderten Abzug frei. 2000 Peseten pro Mann erhielten die Rifkabylen dafür ${ }^{30}$. Zwar träumte Abdelkrim von einer eigenen Währung, aber spanisches Geld blieb im Rif das vorherrschende Zahlungsmittel ${ }^{31}$. Seine Bergbau- und Wirtschaftsverträge mit Europäern dienten auch dem Ziel, Einnahmen für die Modernisierung der Rifarmee zu erzielen. Somit waren genügend Geldmittel zum Ankauf von Kriegsgerät vorhanden.

${ }^{27}$ SHINAR, Abd al-Qadir, S. 172; KHARCHCH, La France, S. 117-119 u. S. 118, Anm. 1; FurNeauX, Abdel Krim, S. 88, S. 191; MOHR, Frankreich, S. 308; Fleming, Primo de Rivera and Abd-el-Krim, S. 116; SLAVIN, Anticolonialism, S. 51; PENNELl, A Country, S. 100, S. 132f;; S. 180; WOOLMAN, Rebels in the Rif, S. 163; SHEEAN, Chief Raisuli, 10.2.1925; GODED LLOPIS, Marruecos, S. 91f.

${ }^{28}$ PRO-FO 371, 8342, 171, 190: Embassy of Madrid an FO, 13.10.1922; PRO-FO 371, 9473, 898, 52: Embassy of Madrid an FO, 31.1.1923.

${ }^{29}$ PA-AA R72042, L057488: Konsulat Tetuan an Botschaft Madrid, 18.6.1923; PRO-FO 371, 9469, 44, 146: Vice-Consul of Tetuan an CG Tangier, 5.3.1923; PRO-FO 371, 9469, 44: CG Tangier an FO, 8.8.1923; KGRNER, La Guerre du Rif espagnole, S. 145; PENNELL, Éxito y fracaso, S. 31, S. 36, Anm. 4; BALfOUR, Deadly Embrace, S. 91; FURNEAUX, Abdel Krim, S. 91.

${ }^{30}$ AN 313 AP 244: Bericht »Rapport Calary« o.D. [Dezember 1924].

${ }^{31}$ MOWRER, Une visite, S. 1524. 


\subsection{Der Schmuggel aus Algerien und aus Französisch-Marokko}

Hauptsächlich bezog Abdelkrim seinen Nachschub aus Algerien bzw. Französisch-Marokko, da diese Grenzen für Spanien nicht kontrollierbar waren. Die Hauptorganisatoren des Schmuggelhandels aus Algerien waren der Franzose Daniel Bourmancé-Say und sein enger Freund Caîd Haddou ben Hammou ${ }^{32}$. Bourmancé-Say hatte einschlägige Erfahrungen. Sein Adoptivvater Louis Say, der im Juli 1900 den Hafenort Port-Say gegründet hatte, betrieb mit den Beqqioua westlich der Bucht von Alhucemas Waffenschmuggel ${ }^{33}$. Ab 1905 belieferte er zusammen mit Daniel Bourmancé und dem Franzosen Gabriel Delbrel Bou Hmara alias Jilani Zerhouni mit Waffen und Munition. Mit der Behauptung, der eigentliche Thronerbe zu sein, leistete Bou Hmara Sultan Abdelaziz seit 1902 Widerstand. Er schaffte es, die Herrschaft im Nordosten Marokkos zu übernehmen ${ }^{34}$.

Bou Hmaras französische Helfer aus Port-Say errichteten bei Restinga in der Nähe von Melilla eine Handelsstation. Ein Dampfer Louis Says, der mit Munition für ihn beladen war, kenterte Ende 1907 bei Mar Chica. Die aufgeschreckten Spanier beschwerten sich über den Waffenschmuggel von Algerien

${ }^{32}$ OTEYZA, Abd-el-Krim, S. 156; PA-AA R72042, L057407: Botschaft Madrid an AA, 17.8.1922. Ein engerer Kontakt mit dem in Paris lebenden Guy Bourmancé-Say, der den Nachlaß seines Vaters Daniel verwaltet, kam nicht zustande. Germain Ayache verwertete die Schriftstücke zum Teil in seinem Buch "La Guerre du Rif» (1996). Zur Biographie Bourmancé-Says: Francis LLABADOR, Port-Say et son fondateur Louis Jean-Baptiste Say, lieutenant de vaisseau de réserve 1852-1915, Oran 1955, S. 39-43, S. 87, S. 239-245; Joseph VALYNSEELE, Les Say et leurs alliances. L'étonnante aventure d'une famille cévenole, Paris 1971, S. 365-368; George W.F. HALLGARTEN, Imperialismus vor 1914. Die soziologischen Grundlagen der Außenpolitik europäischer Großmächte vor dem Ersten Weltkrieg, Bd. 2, München ${ }^{2} 1963$, S. 665f.; AYACHE, La Guerre du Rif, S. 171-187, S. 245f.; KHARCHICH, La France, S. 101f., S. 145-157; DAOUD, Abdelkrim, S. 97-99, S. 126-134; GABRIELLI, Abdel-Krim, S. 7-10, S. 59f.; FONTAINE, L'etrange aventure, S. 126f.; CAOM 10 APOM 295: Bericht "L'affaire riffaine - Abd el Krim« von Robert Montagne, 28.5.1937; AN F7, 13413: Gouverneur général de l'Algérie an MI, Direction des affaires indigènes, 24.7.1925; ADMAE Maroc 133, 117: Bericht "Notes et remarques sur la question riffaine» von Daniel Bourmancé-Say o.D.; SHAT 3H1560: Annexe de Marnia, Algérie, Bericht »Renseignement sur la contrebande d'armes et de munitions de guerre pour les Riffains«, 6.6.1922; ADMAE Maroc 133, 100: Bericht "La question riffaine vue de la méditerranée» von Daniel Bourmancé-Say, 28.5.1925; CADN Maroc DAI 189: Mappe »Bourmancé-Say«.

${ }^{33}$ DAOUD, Abdelkrim, S. 17, S. 98; GABRIELli, Abd-el-Krim, S. 7.

${ }^{34}$ Ross E. DUNN, France, Spain and the Bu Himara Rebellion, in: JOFFE, PENNELl (Hg.), Tribe and State, S. 145-158, S. 145-148; CHARQI, Abdelkrim, S. 13-17; HART, The Aith Waryaghar, S. 361-368; AYACHE, Les origines, S. 129; VILLALOBOS, El sueño colonial, S. 43-47. Nahezu unbekannt ist die Beschreibung Bou Hmaras durch den deutschen Fremdenlegionär Fritz Ohle, der ihn im Herbst 1896 in der Nähe des Salzsees Tigri traf [Fritz OHLE, Der kleine Krieg in Afrika, Berlin 1905, S. 93-101; DERS., Abenteuer und Entdeckungen in Sahara und Atlas, Köln 1928, S. 110-116]. 
ins Rif und besetzten daraufhin am 8. Februar 1908 das Gebiet um Restinga ${ }^{35}$. Die Lieferungen gingen dennoch weiter. Der Händler Nougaret aus Oran verkaufte dem marokkanischen Thronprätendenten über eine Firma aus Lüttich, dem Zentrum des Waffenhandels mit Afrika, 1000-1500 Gewehre und zwei Schnellfeuerkanonen. Ende 1908 jedoch wurde Bou Hmara von der Armee des Sultans gefaßt, in einem offenen Käfig durch die Straßen von Fes gezogen und im August 1909 exekutiert $^{36}$. Seine Organisation des Waffenhandels diente Abdelkrim unter Umständen als Vorbild.

1912 versuchten Jean-Henri Joseph André aus Marseille, Georges Cholvy de Tranoy sowie ihre Partner Auguste Bienboire aus Berkane, Eugène Vépierre aus Paris und der Ecuadorianer Seminario - Herausgeber der Tangerer Zeitung »Journal du Maroc« -, Waffen über Port-Say ins Rif zu liefern. Sie waren auch an Bergbaugeschäften mit dem Rif interessiert. Cholvy de Tranoy hatte im Juli 1912 für acht Tage das Rif bei Iger Aïch aufgesucht und sich dabei als Vertreter der französischen Regierung, die die Rifkabylen mit Waffen beliefern wolle, ausgegeben. An diesem Geschäft waren einige von Abdelkrims späteren Mitstreitern beteiligt: Allouche ben Haddou ben Ali, Haddou ben Hammou, Si Larbi, Abdelkrim ben el Haj Ali Luh und Raïs Messaoud Amar alias Sibbera. Gegen die Bezahlung von 25000 Francs sollte Cholvy de Tranoy in Deutschland oder Belgien Gewehre der Marke Mauser samt Munition erwerben, um sie mit einem Schiff zur Rifküste zu transportieren. Eine Rifdelegation hielt sich zur Klärung des Geschäftes bis November 1912 in Paris auf. Doch die Gesandten bekamen die ersehnten Waffen niemals zu Gesicht $^{37}$. Der Verlauf ähnelte späteren Transaktionen Abdelkrims.

Nach dem Ersten Weltkrieg versuchte Daniel Bourmancé-Say, den wirtschaftlichen Niedergang von Port-Say aufzuhalten, indem er politische und wirtschaftliche Beziehungen zu Abdelkrim aufnahm. Seit 1921 entwickelte sich von Algerien aus ein stetiger Waffennachschub ins Rif. Die Dampfer "Inès« und "Louise« aus Oran fuhren Port-Say an der Westküste Algeriens an, von wo aus die als Pakete deklarierten Waffen per Laster über Tlemcen nach

${ }^{35}$ Fleming, Primo de Rivera and Abd-el-Krim, S. 31; CHANDLER, Spain, S. 304; BouHaSSOUN, La penétration espagnole, S. 120; AYACHE, Les origines, S. 132 u. S. 132, Anm. 35 u. Anm. 38; Hallgarten, Imperialismus, Bd. 2, S. 665f.; PA-AA R16309: Gesandtschaft Tanger an AA, 3.2.1906; CAOM 10 APOM 295: Bericht von Robert Montagne »L'affaire riffaine - Abd el Krim«, 28.5.1937.

${ }^{36}$ DuNN, European Connexion, S. 243, S. 248; Ders., France, S. 148; Gavin WHITE, Firearms in Africa. An Introduction, in: Journal of African History 12 (1971) S. 173-184, S. 182; AYACHE, Les origines, S. 136; WOOLMAN, Rebels in the Rif, S. 41.

${ }^{37}$ Francesco CORREALE, Micro-History of the Modern Maghreb. Traffickers of Weapons in Colonial Morocco. A Case Study: The "Affaire Cholvy de Tranoy \& C.« 1912-1913, in: Middle East History and Theory Workshop at The University of Chicago, 17th Middle East History and Theory Conference (May 10-11, 2002), S. 5-18, URL: http://cas.uchicago.edu/ workshops/mehat/past_conferences/Correale.pdf [31.12.2004]; MADARIAGA, España y el Rif, S. 181f.; CAOM Âlgérie 30H63: Rapport, 7.11.1912. 
Taourirt und Oujda an die Grenze des Rifs transportiert wurden ${ }^{38}$. Der deutsche Botschafter in Madrid zweifelte nicht daran, "dass französische Händler in ziemlich großem Maßstabe die gegen Spanien kämpfenden Riff-Kabylen mit Waffen und Munition versehen haben ${ }^{39}$. Laut der spanischen Zeitung "Libertad« lebte Port-Say vom Schmuggel zur Bucht von Alhucemas ${ }^{40}$.

Caïd Haddou ben Hammou, der lange Jahre in Algerien gelebt hatte und für Abdelkrim nun als Kontaktperson fungierte, richtete in Oujda eine Art Nachschub-Hauptquartier ein. Jede Woche entließ er eine Karawane in Richtung Rif. Wer aus Französisch-Marokko mit dem Rif in Verbindung treten wollte, mußte dies ebenfalls über Haddou tun ${ }^{41}$. Die französischen Behörden blieben untätig. Colonel Huot, der Leiter der Direction des affaires indigènes in Rabat, sagte später dem britischen Journalisten George Ward Price, daß er sehr wohl wisse, daß Caild Haddou in Oujda Waffenschmuggel betreibe. Es sei aber besser zu wissen, wer dies tue, als daß man es nicht wisse ${ }^{42}$.

Die Generalresidenz in Rabat definierte ihre offizielle Haltung nach den ersten Siegen Abdelkrims über die spanischen Truppen als strikte Neutralität. Dennoch entwickelte sich Taourirt zwischen 1921 und 1924 zu einem wahren Markt für unterschiedlichstes Kriegsgerät, nicht zuletzt weil die französischen Beamten der marokkanisch-algerischen Grenze die Nachschublieferungen für das Rif ungehindert passieren ließen ${ }^{43}$. Die Gründe hierfür waren zum einen tiefes Mißtrauen gegenüber Spanien nach der von dessen Einflußzone ausgehenden deutschen »Marokko-Aktion« des Ersten Weltkrieges sowie zum anderen die Strategie, Möglichkeiten für einen Dialog mit Abdelkrim aufrechtzuerhalten. 1922 verdichteten sich die Kontakte auf lokaler Ebene und führten zu einer teilweise recht offenen pro-rifischen Sympathie. Im Juli 1922

${ }^{38}$ SHAT 3H1560: Annexe de Marnia, Algérie, Bericht "Renseignement sur la contrebande d'armes et de munitions de guerre pour les riffains«, 6.6.1922; SHAT 3H1558: Louis-Hubert Lyautey an Commandant de la région de Fès, 11.7.1924; VAlYnSEele, Les Say, S. 368, Anm. 2; LlabadOR, Port-Say, S. 244f.; Walter B. HARRIS, Tangier Problem Dangers. A Base of Intrigue, in: Times, 4.6.1927.

${ }^{39}$ PA-AA R72041, L057362: Botschaft Madrid an AA, 26.12.1921.

${ }^{40}$ PA-AA R72042, L057407: Botschaft Madrid an AA, 17.8.1922 mit Bezug auf einen Bericht der »Libertad《, 15.8.1922.

${ }^{41}$ FonTAINe, L'étrange aventure, S. 75; ShEEAN, Personal History, S. 98; PRO-FO 371, 8356, 7395, 196: Embassy of Madrid an FO, 31.8.1922 mit Bezug auf einen Bericht der »Libertadk.

${ }^{42}$ WARD PRICE, Extra-Special Correspondent, S. 162.

${ }^{43}$ ADMAE Maroc 133, 117: Bericht "Notes et remarques sur la question riffaine« o.D. von Daniel Bourmancé-Say; SHAT 3H1558: RG Rabat an Commandant de la région de Fès, 11.7.1924; CADN Madrid C273: MAE an Ambassade de Madrid, 26.6.1922; SHAT 3H102: EMA, $2^{e}$ bureau, Note, 11.1.1926: PRO-FO 371, 8354, 4882, 54: Bericht $\gg$ Memorandum of a Statement Made by Mr. John Arnall after his Return from a Journey to the Riff", 28.5.1922; SHEEAN, An American, S. 15; KHARCHICH, La France, S. 156; LA PORTE, La atracción del imán, S. 155-158. 
etwa beglückwünschte Capitaine Thierry aus Taourirt Abdelkrim zu seinen Siegen über Spanien und bat ihn, sich nicht vom Feind mit Geld ködern zu lassen, denn er werde ihn mit allem, was er benötige, ausstatten ${ }^{44}$.

Thierry befand sich dabei auf einer Wellenlinie mit Funktionären der Generalresidenz in Rabat. Sie erklärten sich bereit, die Grenze offenzuhalten, um die Auswirkungen der spanischen Seeblockade zu kompensieren. Dies lief auf eine Tolerierung des Schleichhandels mit Waffen heraus ${ }^{45}$. Rifkabylen konnten völlig frei in Marokko oder Algerien gelegene Märkte aufsuchen, um sich dort mit Waffen - meist Gewehren - einzudecken. Schmuggler aus dem Rif erschienen schon bald bei den Beni Ouarain und Marmouchas im Atlasgebir$\mathrm{ge}^{46}$. Am 16. Mai 1922 schrieb Caïd Haddou an Abdelkrim, daß in den Städten Französisch-Marokkos alle erwünschten Handelsgüter erworben werden könn$\operatorname{ten}^{47}$. Aus Oujda und aus Taza gelangten Karawanen mit Lebensmitteln wie Zucker, Tee, Mehl und Grieß ins Rif ${ }^{48}$.

Carlo de Carli, der zusammen mit seinem Partner Berthelier eine Firma in Rabat führte, hatte in Erfahrung gebracht, daß Spanien gegen die Rifkabylen Giftgas einsetzte. De Carli wollte nun Gasmasken zu neun Francs pro Stück verkaufen. Abdelkrim empfing die Reisenden, die am 21. April 1922 von Taourirt aus ins Rif gestartet waren, mit seinem Kriegsrat in Sidi Driss, zeigte aber kein Interesse ${ }^{49}$. Erst als ihm Daniel Bourmancé-Say über Caïd Haddou im Mai 1922 mitteilen ließ, daß in Melilla neues Gas für Spanien angeliefert worden sei, lenkte Abdelkrim ein. Bourmancé-Say erbat vier Monate Zeit, um zusammen mit Carlo de Carli und Berthelier 2000 Gasmasken liefern zu können $^{50}$. Berthelier bot Abdelkrim im Juni 1922 sogar für 5000 Francs eine Ka-

${ }^{44}$ KHARCHICH, La France, S. 147f.; RIVET, Lyautey, Bd. 3, S. 271.

${ }^{45}$ AYACHE, La Guerre du Rif, S. 246; DERS., Les relations franco-espagnoles pendant la Guerre du Rif, in: Españoles y Franceses en la primera mitad del siglo XX, hg. vom Centro de estudios historicos, Madrid 1986, S. 287-293, S. 290; MIEGE, L'arrière-plan diplomatique, S. 226.

${ }^{46}$ HUETZ DE LEMPS, La collaboration, S. 86f.; RIVET, Lyautey, Bd. 3, S. 270f.; HoISINGTON, Lyautey, S. 187; SUEIRO SEOANE, Spanish Colonialism, S. 52, S. 61, Anm. 13; DIES., España, S. 18-24; PA-AA R70870: Botschaft Paris an AA, 21.6.1926 mit beiliegendem Bericht "Affaire Klems«; SHAT 3H1559: Bericht »Déclaration du nommé M'Hand Ould Amar Ou Maaman«, 3.9.1924.

${ }^{47}$ Caîd Haddou an Abdelkrim, 16.5.1922, in: TAHTAH, Pragmatisme 1995, Dok. 14, S. 144 146.

${ }^{48}$ CADN Madrid C273: MAE an Ambassade de Madrid, 26.6.1922; BEVAN, Spain and Morocco II, 23.10.1923.

${ }^{49}$ CADN Madrid C273: MAE an Ambassade de Madrid, 2.6.1922 mit dem Bericht von A. Bourges »Un voyage dans le Riff, Rapport d'un informateur«, 12.5.1922.

${ }^{\text {s0 }}$ Caîd Haddou an Abdelkrim, 16.5.1922, in: TAHTAH, Pragmatisme 1995, Dok. 14, S. 144 146. 
none an, die Gasgranaten - 60 Francs pro Stück - abschießen konnte ${ }^{51}$. Wie bei so vielen Geschäften der Rifkabylen ist auch hier nichts über die Verwirklichung bzw. die Gründe für die Nicht-Verwirklichung bekannt.

Über Taourirt und Taza belieferte Messaoud Bendrao aus Tanger das Rif mit Salz ${ }^{52}$. Bendrao war Präsident der Gesellschaft Hakhnassat Orahim, Mitglied der spanischen Handelskammer von Tanger und einer der wichtigsten Geschäftsleute Marokkos ${ }^{53}$. Rifkabylen erwarben in Fes Vieh und trieben es zur spanischen Zone. Schiffe der Société maritime nationale und der Compagnie Sicard lieferten militärisches Gerät an die Rifküste ${ }^{54}$.

Der Handel zwischen Franzosen und dem Rif war nicht geheimzuhalten. Die deutsche Botschaft in Madrid berichtete im Juli 1922, „dass die Zufuehrung von Waffen und Munition aus der franzoesischen Zone in die spanische neuerdings wieder sehr zugenommen hat ${ }^{55}$, und auch die britische Botschaft meldete, daB Franzosen in der Lage waren, mit Wissen ihrer Behörden Schmuggel zu betreiben ${ }^{56}$. In Melilla diskutierten Europäer öffentlich, daß Frankreich das Rif mit Nachschub unterstützte ${ }^{57}$. Die britische Gesandtschaft in Tanger hatte keinen Zweifel daran, daß in nächtlichen Märschen Gewehre aus Algerien ins Rif transportiert wurden ${ }^{58}$. Der Brite John Bevan, der sich im Sommer 1923 für drei Monate im Rif aufhielt, vermutete ein stilles Einverständnis zwischen Abdelkrim und den französischen Behörden Marokkos und Algeriens ${ }^{59}$. Abdelkrim war sich bei alldem bewußt, daß es bei einer etwaigen feindlichen Haltung Frankreichs um die Nachschubversorgung des Rifs schlecht bestellt sein würde ${ }^{60}$.

Der Großteil des benötigten Materials für das Feldtelefonnetz stammte aus Algerien. Im Frühjahr 1922 hatte Abdelkrim bereits mit dem Franzosen Jean du Taillis über den Ankauf einer kompletten Telefonlinie mit 40 Stationen und

\footnotetext{
${ }^{51}$ KHARCHICH, La France, S. 155 u. S. 155, Anm. 4; CADN Maroc DAI 198: Caïd Haddou an Abdelkrim, 24.6.1922.

32 SHAT 3H1559: Centre des renseignements extérieurs du Maroc, Renseignements, 21.11.1923.

${ }^{33}$ Abraham I. LAREDO, Les noms des Juifs du Maroc. Essai d'onomastique judéo-marocaine, Madrid 1978 (Consejo superior de investigaciones cientificas, Instituto de Filologia, E, 3), S. 509; Mark M. SERELS, A History of the Jews of Tangier in the Nineteenth and Twentieth Centuries, New York 1991, S. 264.

${ }^{54}$ LA PORTE, La atracción del imán, S. $155 f$.

${ }^{55}$ PA-AA R71125, K430274: Botschaft Madrid an AA, 21.7.1922.

${ }^{56}$ PRO-FO 371, 8356, 7395, 196: Embassy of Madrid an FO, 31.8.1922.

${ }^{57}$ SHAT 3H1559: Contrôle civil de Beni Snassen an Contrôleur en chef de la région d'Oujda, 18.12.1923.

${ }^{58}$ PRO-FO 371, 9470, 44, 126: CG Tangier an FO, 13.10.1923.

${ }^{59}$ BEVAN, Spain and Morocco II, 23.10.1923.

${ }^{60}$ PRO-FO 371, 9470, 44, 29: CG Tangier an FO, 2.9.1923 mit Bezug auf Aussagen von John Bevan.
} 
120 Kilometer Draht verhandelt ${ }^{61}$. Anfang September 1923 transportierten Caĩd Haddou und drei Franzosen aus Algerien Telefon-Material nach Ajdir ${ }^{62}$. Ende September 1923 schrieb Abdelkrim an seinen Außenminister Azerkane, daß er Haddou 2000 Peseten für den Ankauf von Telefonausrüstung in Algerien übergeben solle ${ }^{63}$.

Am 23. Oktober 1923 verhandelte Haddou telefonisch mit der Firma Thirion in Oujda, die elektrische Apparate vertrieb, über den Preis von Isolatoren. Kurze Zeit später - am 13. November 1923 - begab sich ein Publizist aus Oran namens André Guibert mit dem Zug nach Oujda. Er führte vier tragbare Feldtelefone der Marke Duophone mit sich, die Caïd Haddou übergeben werden sollten. Zur Tarnung für die französischen Behörden hatte die Firma von Guillaume Loubiès sie bei Thirion gekauft und zu Guibert nach Oran geschickt. Sieben Mulis transportierten nun von Oujda aus 32 Telefonmasten, 49 Rollen Isolierband, 1800 Isolatoren und Ersatzteile zur Firma Quincaillerie bac, métaux et armes nach El Aïoun und von dort nach Taourirt zum Mittelsmann Badarous. Doch in Taourirt beschlagnahmte das französische Militär das gesamte Material ${ }^{64}$. Der Algerienfranzose P. Robert erschien daraufhin im Büro von Capitaine Vincent in Guercif und beschwerte sich, daß es ein Fehler sei, den Nachschub ins Rif zu behindern, da Abdelkrim Frankreich sehr ergeben sei $^{65}$. Verärgert fragte Caîd Haddou telegrafisch beim Kontrollbeamten Léon Gabrielli nach, ob dieser den Nachschub für das Telefonnetz tatsächlich als Waffenschmuggel betrachte ${ }^{66}$.

Erst Anfang 1924, als die Rifkabylen versuchten, in Algerien Flugzeuge zu kaufen, wies das französische Außenministerium den dortigen Generalgouverneur an, jeglichen Waffenhandel zu unterbinden ${ }^{67}$. Im Februar 1924 wurde der Franzose Lobiede, der einen Vertrag für den Verkauf von Mauser-Gewehren an das Rif bei sich trug, in Oran verhaftet ${ }^{68}$. Die französischen Behörden waren angesichts spanischer Proteste und heftiger Presseberichte vorsichtiger ge-

${ }^{61}$ ADMAE Maroc 112, 221: Jean du Taillis an Abdelkrim, 14.4.1922; ADMAE Maroc 112, 250: Jean du Taillis an Si M'hammed o.D. [1922].

${ }^{62}$ SHAT 3H1559: Région de Taza, Cercle de Guercif, SR, Feuille de renseignements, 10.9.1923.

${ }^{63}$ PENNELL, A Country, S. 151.

64 ADMAE Maroc 219, 27: RG Rabat an MAE, 9.1.1924; SHAT 3H1559: Commissariat de la sûreté régionale Oujda, Renseignements, 24.10.1923 und 20.11.1923; CADN Maroc DAI 192: Commissariat de la sûreté régionale Oujda, Renseignements, 11.1.1924; SHAT 3H1102: Chef de bureau de renseignements Taourirt an Commandant le cercle de Guercif, 4.1.1924 und 23.2.1924.

${ }^{65}$ SHAT 3H1102: Territoire de Taza, Cercle de Guercif, SR, Feuille de renseignements, 22.1.1924.

${ }^{66}$ CADN Maroc DAI 192: Chef de la région d'Oujda an RG Rabat, 15.2.1924.

${ }^{67}$ ADMAE Maroc 219, 34: MAE an Gouverneur général de l'Algérie, 16.1.1924; HUETZ DE LEMPS, La collaboration, S. 87. Siehe hierzu S. 197.

${ }^{68}$ Cremadeills, Le Parti communiste français, Bd. 1, S. 77. 
worden $^{69}$. Als der britische Reporter George Ward Price im März 1924 von Französisch-Marokko aus ins Rif einreisen wollte, lehnte dies die Generalresidenz in Rabat mit der Begründung ab, daß Frankreich nicht verdächtigt werden wolle, Schmuggel mit dem Rif zu betreiben ${ }^{70}$. Die Grenzstreitigkeiten mit Abdelkrim um das Gebiet am Ouergha-Fluß im Sommer 1924 führten zu einer weiteren Verschärfung der französischen Haltung. Urbain Blanc von der Generalresidenz in Rabat befahl eine sehr aufmerksame Überwachung der Grenzgebiete und eine strikte Konfiszierung jeglichen Kriegsmaterials ${ }^{71}$.

Trotzdem versiegte der Nachschub ins Rif nicht. Der Makler Joseph Abad und sein Partner Henri Guigal schlossen am 21. Juni 1924 einen Vertrag mit der Rifregierung $a b$, der sie zum Hauptlieferanten für die benötigten Versorgungsgüter bestimmte ${ }^{72}$. Technisches Gerät, Pioniermaterial, Hacken, Schaufeln, Werkzeug aller Art oder Eisendraht wurden ins Rif transportiert ${ }^{73}$. André Guibert bot Caïd Haddou alles Erforderliche für den Bau einer Zementfabrik inklusive 300 Tonnen Kalk, einer Dampfmaschine und eines Dynamos der Marke Thomson-Houston ${ }^{2}{ }^{74}$. Caïd Haddou stand mit dem Uhrengeschäft Gabriel in Oujda in Kontakt, verhandelte mit dem Industriellen Peyval, dem Elektriker Michel, dem Baustoffhändler Moha sowie dem Stoffhändler Karsenty und kümmerte sich im Zuge einer Verkaufsannonce in der Zeitung "Écho d'Oran« um den Kauf des Motorbootes "Amélie «"

Der britische Vizekonsul von Fes, Gilbert MacKereth, erfuhr von einem Rifkabylen, daß Abdelkrim von einer französischen Firma in Algerien zwei weitere Motorboote erhalten habe ${ }^{76}$. Abdelkrims Autos stammten aus Algerien. Der Renault 18 HP wurde dem Franzosen Guissani abgekauft, und Auguste Moulièras aus Oran verdiente 42000 Francs am Verkauf seines Ford $^{77}$. Die Autohändler P. Rouget und Deloys aus Oujda lieferten Ersatzteile und Benzin, und auch Daniel Bourmancé-Say kümmerte sich um Nachschub an $\mathrm{Sprit}^{78}$.

${ }^{69}$ ADMAE Maroc 219, 96: Ambassade de Madrid an MG, EMA, $2^{\mathrm{e}}$ bureau, 27.3.1924.

${ }^{70}$ George WARD PRICE, The Journey, in: Daily Mail, 26.4.1924.

${ }^{71}$ CADN Maroc DAI 195: RG Rabat an Chef de la région d'Oujda, 28.7.1924.

7 ADMAE Maroc 220, 153: Vertrag zwischen der Rifregierung und Joseph Abad sowie Henri Guigal, 21.6.1924.

${ }^{73}$ ADMAE Maroc 133, 117: Bericht »Notes et remarques« von Daniel Bourmancé-Say.

${ }^{74}$ CADN Maroc DAI 190: André Guibert an Caïd Haddou, 24.9.1924.

${ }^{75}$ CADN Maroc DAI 190: Caïd Haddou an »Horlogerie Gabriel«, Oujda, 8.8.1924; ADMAE Maroc 219, 141 und 144: Gouverneur général de l'Algérie an MAE, 6.9.1924 und 7.10.1924.

${ }^{76}$ PRO-FO 174, 303, 74: Vice Consul of Fez an CG Rabat, 27.11.1924.

${ }^{77}$ ADMAE 133, 117: Bericht "Notes et remarques« von Daniel Bourmancé-Say; SHAT 3H1561: EMA, 2־ureau, Fès, Bericht »Renseignements divers fournis par Antonio Palma«, 1.1.1926.

${ }^{78}$ CADN Maroc DAI 190: Mappe »Pierre Ghisolfik, Note, 31.10.1924; CADN Maroc DAI 195: RG Rabat an Chef de la région d'Oujda, 5.11.1924. 
Ein Teil des Handels zwischen Algerien und dem Rif lief über die Compagnie berbère in Camp Berteaux und Oujda $a b^{79}$. Waffenhändler aus Oran belieferten das Rif über das Meer. So wurden Anfang Dezember 1924 Gewehre der Marke Lebel in einer Bucht bei Ajdir entladen. Die nötige Munition besorgte sich Abdelkrim in der französischen Zone Marokkos ${ }^{80}$. Als Waffenschmuggler hatten die Behörden Französisch-Marokkos den Grundstücksmakler Proussard im Visier, der mit Abdelkrim in Verbindung stand und versuchte, ins Rif zu gelangen ${ }^{81}$.

Aus Marseille beförderten kleine Boote Waffen und Munition zu algerischen Häfen, von wo sie über eine Korkfarm bei Taza weiter ins Rif geleitet wurden $^{82}$. Maschinengewehre, Munition und sogar leichte Artillerie gelangten den Berichten des amerikanischen Journalisten Vincent Sheean zufolge von Algerien aus ins Rif. Er schätzte bei seinem Rifbesuch im Januar 1925, daß 90\% aller importierten Schmuggelware aus der französischen Zone Marokkos oder aus Algerien stammte ${ }^{83}$. „Times«-Korrespondent Walter Harris berichtete dem britischen Vertreter in Tanger Robert Clive, im Besitz von Beweisen über den von Frankreich gestützten Waffenschmuggel zu sein ${ }^{84}$. Spaniens Diktator Primo de Rivera zeigte dem amerikanischen Journalisten Webb Miller während eines Interviews im November 1924 französische Munition, die toten Rifsoldaten abgenommen worden war. Rivera zufolge waren die Patronen aus Französisch-Marokko ins Rif geschmuggelt worden: $m$ Denken Sie an meine Worte, wenn Abd el-Krim mit uns fertig ist, wird er die Franzosen angreifen und ihre eigene Munition gegen sie verwenden ${ }^{85}{ }^{85}$. Bis zum Frühjahr 1925 warfen die Spanier Frankreich vor, das Rif mit Waffen zu versorgen ${ }^{86}$.

Angesichts der verheerenden Aussicht, daß die an Abdelkrim gelieferten Waffen gegen die eigenen Soldaten gerichtet werden könnten, wies das französische Außenministerium den Nachrichtendienst des Innenressorts an, energische Gegenmaßnahmen einzuleiten ${ }^{87}$. Nach Abdelkrims Angriff auf. Französisch-Marokko im April 1925 - hierbei erbeuteten die Rifkabylen ebenfalls

${ }^{79}$ SHAT 3H1561: EMA, $2{ }^{\mathrm{e}}$ bureau, Fès, Bericht "Renseignements divers fournis par Antonio Palmak, 1.1.1926.

${ }^{80}$ SHAT 3H1557: Contrôle civil de Taourirt, Bulletin de renseignements, 8.12.1924 mit Bezug auf Aussagen von El Hadi ben Dadi.

${ }^{81}$ SHAT 3H1557: RG Rabat, DAI, Bericht »Agissements étrangers dans le Riff«, 10.9.1924.

22 FLEMING, Primo de Rivera and Abd-el-Krim, S. 222.

${ }^{83}$ SheEAN, War in Africa, S. 260; DERS., Riffis Fight, 12.2.1925; DERS., Personal History, S. 98.

${ }^{84}$ PRO-FO 371, 11909, 5, 267: CG Tangier an FO, 11.6.1926.

${ }^{85}$ MILLER, Frieden, S. 169.

${ }^{86}$ SUEIRO SEOANE, Contrabando, S. 261; HUETZ DE LEMPS, La collaboration, S. 89; FLEMING, Primo de Rivera and Abd-el-Krim, S. 222.

${ }^{87}$ ADMAE Maroc 219, 175: MAE an MI, Sûreté générale, 2.1.1925. 
Waffen und Munition ${ }^{88}$ - versuchten die französischen Militärs, die Nachschubwege vor allem von Algerien aus zu unterbrechen. Ein Bericht des Generalstabs schlug die Überwachung der verdächtigen algerischen Häfen Dar Sebabna und Port-Say sowie des Landweges von Oran über Oujda nach Taourirt vor $^{89}$. Im Zeitraum zwischen Juni und Juli 1925 einigten sich Frankreich und Spanien über eine Seeblockade vor der Rifküste ${ }^{90}$. Doch noch bis zum September 1925 erhielt Abdelkrim einem britischen Bericht zufolge konstante Munitionslieferungen aus Oran: "Warum die algerischen Behörden dies bei Kriegsausbruch nicht sofort unterbanden, ist rätselhaft" ${ }^{91}$.

In der Tat ging der Schmuggel von Algerien und Französisch-Marokko aus weiter - wenn auch stark eingeschränkt. Der deutsche Deserteur Josef Klems tippte Si M'hammeds Bestellungen für Waffen, Nachschub und Versorgungsgüter in seine Schreibmaschine ${ }^{92}$. In der Nähe des algerischen Cap de l'eau wurde ein Mann namens Saez verdächtigt, wegen Waffenlieferungen mit dem Rif in Kontakt zu stehen ${ }^{93}$. Waffenkonvois erreichten von Port-Say aus das Rif, berichtete das «Journal « im Juli $1925^{94}$. Von Izmourne aus dirigierte Caïd Haddou die Nachschublieferungen mit Hilfe seiner Vermittler Zerouki, Pierre Ghisolfi, Athias, Pugéol, P. Robert und Dr. Yves Marion-Gallois aus Oujda, Eugène Allard aus Oran sowie Kitchin, dem englischen Leiter des EisenerzBergwerkes von Sebabna in Algerien ${ }^{95}$.

Alle zwei Wochen führte der Marokkaner Bou Tahar Nachschubkarawanen von Oujda aus in Richtung Rif. Noch im April 1926 kaufte Si M'hammed von den Beni Berber in Französisch-Marokko 125000 SchuB Munition für LebelGewehre $^{96}$. Der Italiener Mario Magri, der sich vom September 1925 bis Februar 1926 im Rif aufhielt, berichtete, zahlreiche Karawanen gesehen zu

${ }^{88}$ USBORNE, The Conquest, S. 283; Larry RUE, Riff Warriors Make Big Hauls. Tribune Man Views War Spoils, in: Chicago Tribune, 25.6.1925.

${ }^{89}$ ADMAE Maroc 220, 145: MG, EMA an MAE, 2.7.1925.

${ }^{90}$ ESPAÑA, La actuación, S. 70-73.

91 PRO-AIR 5, 722: Bericht »A Study of the Air Aspect of the France-Riff War 1925-1926» von Lt. D.L. Blackford (1930), S. 19.

${ }^{92}$ CADN Maroc DAI 199: EMA, $2^{\circ}$ bureau an RG Rabat, 6.7.1926 mit dem Bericht "Note sur les renseignements fournis par le légionnaire Klems du $2^{\circ}$ etranger et leur exploitation« o.D.

${ }^{93}$ CAOM Algérie 1CM1: Contrôle civil des Beni Snassen an Chef de la région d'Oujda, 17.6.1925.

${ }^{9}$ La contrebande de guerre aux abords du Riff est une industrie puissante et organisée, in: Journal, 25.7.1925.

${ }^{95}$ ADMAE Maroc 99, 244: EMA, $2{ }^{e}$ bureau, Bericht "Renseignements sur Abd el Krim et sur la contrebande d'armes au Maroc«, 2.9.1925; CADN Madrid C263: MAE an Ambassade de Madrid 4.9.1925; ADMAE Maroc 101, 19: MAE an RG Rabat, 21.4.1926; SHAT 3H102: MG, EMA, $2^{\mathfrak{e}}$ bureau, Bericht "Rapport au sujet de la contrebande s'exercant entre la province d'Oran et le Riff «, 10.6.1925.

${ }^{96}$ SHAT 3H442: Note de renseignements o.D. [Mitte 1926] mit Bezug auf Aussagen des deutschen Deserteurs Karl Ohme. 
haben, die Nachschub aus Ouezzane und Fes (Französisch-Marokko) ins Rif beförderten ${ }^{97}$. Henri Laffont, ein Franzose aus Fes, fiel ins Visier der französischen Behörden, weil er in der spanischen Zone häufig seinen Aufenthaltsort wechselte und sich in Gibraltar mit Abdelkrims politischem Berater Robert Gordon-Canning traf ${ }^{98}$. Nach Kriegsende verhafteten spanische Soldaten Laffont in der Nähe von Ajdir unter Anklage des Waffenschmuggels für Abdelkrim $^{99}$.

\subsection{Der Nachschub aus Tanger}

Tanger - »die Zitadelle der Schmuggler ${ }^{100}$ - diente Abdelkrim während des Rifkrieges als eine der Hauptbasen für Nachschublieferungen ${ }^{101}$. Die Verbindungen zwischen dem Rif und Tanger hatten Tradition, denn viele Rifkabylen lebten in der Hafenstadt ${ }^{102}$. Kurz nach dem Sieg von Annual hefteten Agenten Abdelkrims einen Appell an die Tür der Tangerer Hauptmoschee, in dem nicht nur zur Beteiligung am Kampf gegen Spanien, sondern auch zur Versorgung des Rifs mit Munition aufgerufen wurde ${ }^{103}$.

Der Schmuggel aus Tanger nicht nur von Waffen, sondern auch von Versorgungsgütern und Lebensmitteln aller Art wurde den Rifkabylen anfangs sehr leicht gemacht. Der britische Konsul von Tetuan fragte sich, wie die spanischen Truppen mit ihrer Taktik, sich praktisch nur in ihren Blockhäusern aufzuhalten, verhindern wollten, daß Abdelkrim sein Waffenarsenal aufstocken konnte ${ }^{104}$. Die französische Generalresidenz in Rabat warf den Spaniern noch im Januar 1925 vor, bis dato nichts unternommen zu haben, um den Nachschub Abdelkrims aufzuhalten ${ }^{105}$. Eine völlige Blockade der internationalen Zone Tangers war wegen des gebirgigen Geländes schwer möglich. Daher gelang es Versorgungskarawanen der Rifkabylen immer wieder, die spanischen Truppen heimlich zu passieren. Abdelkrims Tangerer Agent Si Abdelkrim ben el Haj Ali Luh - kurz: „Ali Luh« - übernahm nach dem Ausbruch

${ }^{97}$ SHAT 3H102: RG Rabat an MG, EMA, $2^{\mathrm{e}}$ bureau, 13.2.1926 mit Bezug auf Aussagen von Mario Magri.

${ }^{98}$ CADN Tanger C38: RG Rabat, DAI, Renseignements, 13.3.1926.

${ }^{99}$ CADN Tanger C40: CG Tanger, Renseignements, 25.9.1926.

${ }^{100}$ Pierre LOZE, Chez eux qui ravitaillent les rebelles riffaines, in: Petit Journal, 12.4.1926.

${ }^{101}$ WOOLMAN, Rebels in the Rif, S. 155.

${ }^{102}$ David M. HART, Notes on the Riffian Community of Tangier, in: The Middle East Journal 11 (1957) S. 135-169.

${ }^{103}$ PRO-FO 371, 7067, 184, 105: CG Tangier an FO, 6.8.1921.

${ }^{104}$ PRO-FO 371, 8341, 171, 86: Vice Consul of Tetuan an CG Tangier, 28.12.1921.

${ }^{105}$ CADN Madrid C263: RG Rabat an MAE, 23.1.1925. 
des Rifkrieges bis zu seiner Ausweisung aus der internationalen Zone von Tanger Ende 1924 die Organisation des Nachschubs ${ }^{106}$. Sein Nachfolger wurde der in Souani bei Tanger lebende El Haj Mustafa ${ }^{107}$. Größere Geschäfte liefen über Abdelkrims Tangerer Repräsentanten Moulay Ali el Khamlichi und Haddou ben Ali el Muqaddam $a b^{108}$. Ahmed Kheriro, Abdelkrims Kommandant im Westen des Rif-Einflußbereichs, war für die sichere Durchquerung der Konvois in der Jebala-Region verantwortlich ${ }^{109}$.

In aller Öffentlichkeit wurde in den Tangerer Straßen Munition verkauft, und ganz offen bepackten die Rifkabylen dort ihre Lasttiere. Im Schutz der Dunkelheit verließen die Karawanen die Stadt und wurden an der Grenze zur spanischen Zone von bewaffneten Rifeinheiten empfangen, die sie dann durch die spanischen Linien nach Taghzout, Chichaouen oder Aït Kamara führten ${ }^{110}$. Der Überläufer Richard Sablotny beobachtete im Oktober 1924 bei Tanger: »Aus Verstecken und aus geheimen Pfaden entlang der Hügel kamen Karawanen von Mulis, die mit Bündeln beladen waren und von Frauen, Kindern und alten Männern begleitet wurden, die Pakete und Körbe allerlei Größe trugen. Schmuggler aus dem Rif ${ }^{\prime \prime \prime}$.

Als der deutsche Deserteur Kurt Degenkolbe im Sommer 1925 das Rif verließ, begleitete er eine Karawane, die sich bei Souk el Arba bildete. Etliche hundert Mann hatten Maultiere, Esel und Pferde mit Kif, Feigen und Halfagras beladen, um in Tanger Zucker, Tee und Munition einzutauschen ${ }^{112}$. Daniel Bourmancé-Say berichtete der französischen Polizei in Tanger, er habe zahlreiche Konvois die Stadt verlassen sehen ${ }^{113}$. In der Nacht vom 17. auf den 18. August 1925 etwa wurde der französische Journalist Jacques RogerMathieu am Ende einer langen Maultier-Kolonne an den spanischen Posten vorbeigeführt $^{114}$. Sein amerikanischer Kollege Vincent Sheean passierte den Ring um Tanger im September 1925 ohne Mühe: „Dieser Teil des Blockadebruchs verdient besondere Aufmerksamkeit deshalb, weil ganz dasselbe jede Nacht sich ereignet und so die Unmöglichkeit in sich zeigt, in solch einem

${ }^{106}$ SPENCER PrYSE, Through the Lines, S. 855; PENNELL, A Country, S. 55; Angelo GHIRELLI, Monografia de la kabila de Bokoia, in: Archivo del Instituto de estudios africanos de Madrid 8 (1955) S. 27-83, S. $81 \mathrm{f}$.

${ }^{107}$ CADN Tanger C37: Région de Fès, SR, Bulletin de renseignements, 7.12.1925.

${ }^{108}$ SHAT 3H1 103: Contrôle civil de Taourirt, Bulletin de renseignements, 23.9.1924.

${ }^{109}$ CADN Tanger C37: Région de Fès, SR, Bulletin de renseignements, 5.11.1925.

${ }^{110}$ PRO-FO 371, 11079, 39, 139: Embassy of Madrid an FO, 18.7.1925 mit einem beigefügten Bericht des US-amerikanischen Militärattachés »C.B.H.« o.D. (Juli 1925); TERRIER, Les "Frères de la côte« 1925, S. 549; WOOLMAN, Rebels in the Rif, S. 155.

11 SABLOTNY, Légionnaire, S. 299.

${ }^{112}$ DEGENKOLBE, Vom Schusterjungen, S. 116.

${ }^{113}$ CADN Tanger C39: Tabor de police $\mathrm{N}^{\circ} 1$, Bericht Note au sujet de Mr. B....S.... (Bourmancé-Say)«, 7.11.1925.

114 Jacques ROGER-MATHIEU, La périlleuse traversée des lignes espagnoles. Un combat de nuit sur la route de Msouha, in: Matin, 6.9.1925. 
Lande eine effektive Blockade aufrechtzuerhalten ${ }^{115}$. Mit ihm entwischten 300 Rifkabylen sowie die mitgeführten Maultiere, Esel, Hühner und Geißböcke dem nächtlichen Kreuzfeuer zweier spanischer Festungen ${ }^{116}$. Sheeans Bericht wurde durch französische Beobachtungen bestätigt, wonach allein zwischen dem 1. und dem 15. Dezember 19251710 Tiere den spanischen Sperriegel durchquerten. Lediglich sechs von ihnen fielen den Schüssen spanischer Soldaten zum Opfer. Ein Rifbegleiter starb, ein weiterer wurde verwun$\operatorname{det}^{117}$.

In Tanger lebende Geschäftsleute und Europäer, die mit Abdelkrim sympathisierten, leisteten Hilfestellung in Form von Schmuggelgeschäften ${ }^{118}$. Einige Personen waren bekannt, ohne daß etwas gegen sie unternommen wurde. Der Kutscher Victor Berlier, Edmond el Lezrah, der Grundstücksmakler und Besitzer einer Strandbar Brossard, der frühere Besitzer der "Villa Harris« Jack Ganzelevitch und José Sotiry wurden in einem spanischen Bericht als Rifschmuggler identifiziert ${ }^{19}$. Den Brüdern Lucien und Emile Bonnet wurde nachgewiesen, daß sie mit Kabylen der spanischen Zone Marokkos Waffenhandel betrieben. Der Belgier Grotelot reparierte für Rifkämpfer Waffen ${ }^{120}$. Einige organisierten lediglich von Tanger aus die Schmuggellieferungen ${ }^{121}$. Im April 1925 etwa charterte der Italiener Petri aus Tanger den spanischen Dampfer »Jacinto«, der aus Italien stammende Munition an der Rifküste entlud ${ }^{122}$.

Der bekannteste Waffenschmuggler in Tanger wurde "El buzo« (der Taucher) genannt. Er hatte sich auf Transporte über das Meer spezialisiert ${ }^{123}$. Es handelte sich um den Spanier Pedro Conde. Im Juni 1923 hatte El buzo bereits den Engländer Louis de La Garde auf einem Schmuggelschiff von Gibraitar aus zur Rifküste befördert ${ }^{124}$. In der Nacht vom 9. auf den 10. Januar 1926 verhandelte Abdelkrims politischer Berater Robert Gordon-Canning mit Conde und seinem italienischen Mechaniker auf deren im Tangerer Hafen liegenden

115 SHEEAN, Im Hauptquartier, 2.10.1925.

${ }^{116}$ DERS., Im Rif, 29.9.1925.

${ }^{117}$ CADN Tanger C37: Tabor de police $\mathrm{N}^{\circ}$ 1, Bericht »Ravitaillement par Tanger, des indigènes de la zone espagnole« o.D. [1925].

${ }_{118}$ WOOLMAN, Rebels in the Rif, S. 126; VAIDON, Tangier, S. 199.

${ }^{119}$ PRO-FO 371, 12687, 11, 190: Ambassade de Londres an FO, 25.2.1927 mit dem aus Spanien stammenden Bericht »Annexe au memorandum presenté par le gouvernement de sa Majesté«, 15.2.1927. Vgl. CADN Tanger A427: Centre de renseignements extérieurs du Maroc, Tanger an CG Tanger, 30.6.1922.

${ }^{120}$ CADN Tanger C38: Tabor de police $\mathrm{N}^{\circ} 1$, Information, 17.10.1925; CADN Tanger C40: Tabor de police $\mathrm{N}^{\circ} 1$, Renseignements, 27.2.1926.

${ }^{121}$ HARRIS, Tangier Problem, 4.6.1927.

${ }^{122}$ CADN Maroc DAI 194: Bericht »Note au sujet du ravitaillement en armes et munitions du Rif par mer«, 30.5.1925.

${ }^{123}$ DUMAS, Abd-el-Krim, S. 47; LOZE, Tanger, 6.4.1926.

${ }^{124}$ PRO-FO 371, 12692, 236, 28: WO an FO, 16.8.1927 mit einem beiliegenden Brief von Louis de La Garde, 28.7.1927. 
Boot »Africa《 über den Transport von Medikamenten und Benzin ins Rif ${ }^{125}$. Der Holländer Martinous Pels de Fons Ybacato führte mit seiner Ehefrau in Tanger einen Kolonialwarenladen mit Geschäftsbeziehungen nach Larache. Er war ein enger Vertrauter vom Tangerer Vertreter der British Red Crescent Society, Captain S. Cyril Beresford Mundey ${ }^{126}$. Wegen seiner Waffengeschäfte mit dem Rif, die er über Gibraltar führte, wurde Pels Anfang 1927 aus der spanischen Zone ausgewiesen ${ }^{127}$.

Einige mit dem Rif sympathisierende Briten waren in Tanger aktiv. Der englische Wasserlieferant Peneth schmuggelte in seinem Auto Waffen und Munition bis zur Grenze der internationalen Zone ${ }^{128}$. John Arnall verknüpfte humanitäre Hilfsmaßnahmen mit politischen und wirtschaftlichen Interessen im Rif. Dafür waren ihm alle Methoden recht - auch Waffenschmuggel. Mit Schiffen seiner British Riff Company versorgte Amall die Rifkabylen seit 1919 bereits mit Lebensmitteln. Da das Rif 1921 die beste Ernte seit Jahrzehnten verzeichnen konnte, war diese Art der Nachschublieferungen nicht länger erforderlich. Das letzte Versorgungsschiff Arnalls erreichte das Rif im Januar $1922^{129}$.

Eigenen Aussagen zufolge lieferte Arnall den Rifkabylen 1921 große Mengen an Munition ${ }^{130}$. Zusammen mit zwei Helfern gedachte er den Schmuggel noch auszuweiten. Sein Geschäftspartner sollte in Spanien Waffen aufkaufen und mit kleinen Booten an die Rifküste befördern. Hierbei handelte es sich um Messaoud Benaïm, einen auf der Insel Nokour lebenden jüdischen Händler, den eine enge Freundschaft mit Abdelkrim verband. Er diente als Mittelsmann zwischen Abdelkrim und dem Militärgouverneur von Melilla ${ }^{131}$. Über den Spanier Antonio Venco sollten spanische Verwaltungsbeamte bestochen werden, damit der Handel ungestört ablaufen konnte. Die Gruppe erhoffte sich als Gegenleistung den Ankauf von Gelände und Bergbaugebieten. Das Interesse im Rif war angesichts der Kriegsbeute aus Annual gering ${ }^{132}$.

${ }^{125}$ ADMAE Maroc 135, 116: Tabor de police $\mathrm{N}^{\circ}$ 1, Information, 11.1.1926.

${ }^{126}$ CADN Tanger C40: Tabor de police $\mathrm{N}^{\circ}$ 1, Renseignements, 7.3.1926 und 8.4.1926.

${ }^{127}$ CADN Madrid C263: Consul de Gibraltar an Ambassade de Madrid, 30.1.1926; ADMAE Maroc 100, 216: EMA, $2^{\complement}$ bureau, Note de renseignements, 12.3.1926; PRO-FO 371, 12687, 11, 190: Ambassade de Londres an FO, 25.2.1927.

${ }^{128}$ PRO-FO 371, 12687, 11, 190: Ambassade de Londres an FO, 25.2.1927 mit dem Bericht "Annexe au memorandum presenté par le Gouvernement de sa Majesték, 15.2.1927.

${ }^{129}$ CADN Tanger A427: Renseignements, 31.3.1922. Siehe zu John Arnall Kapitel 3, S. 64 67 und Kapitel 6, S. 264-285.

${ }^{130}$ CADN Madrid C263: RG Rabat an MAE, 8.5.1922; RIVET, Le commandement francais, S. 107.

${ }_{131}$ Mohammed KenBIB, Juifs et musulmans au Maroc 1859-1948. Contribution à l'histoire des relations inter-communautaires en terre d'Islam, Rabat 1994, S. 445; AYACHE, Les origines, S. 153 u. S. 153, Anm. 21; MADARIAGA, España y el Rif, S. 481.

${ }_{132}$ CADN Tanger A427: Renseignements du drogmanat, 28.3.1922; CADN Londres C523: MAE an Ambassade de Londres, 24.4.1922. 
Als John Arnall im März 1922 um Erlaubnis für einen Rifbesuch bat, bestellte Abdelkrim 400 Handgranaten ${ }^{133}$. Spaniens Botschafter in London, Alfonso Merry del Val, beschwerte sich beim britischen Außenministerium, daß Arnall in Großbritannien Flugzeuge, Giftgas-Bomben, Waffen und Munition kaufen wolle ${ }^{134}$. Im September 1922 schickte der ungeduldige Abdelkrim einen Kurier zu Arnalls Ehefrau Gertrude nach Tanger, um sich nach dem Verbleib des Materials zu erkundigen ${ }^{135}$. Doch Arnalls Bemühungen in seinem Heimatland scheiterten.

Bis zu seinem Tod am 11. März 1924 versuchte er sich mit einer Gruppe aus Tanger und Gibraltar im Waffenschmuggel. Vor der Ghomaraküste kaperten spanische Schiffe ihren aus Gibraltar kommenden Dampfer, der Waffen mit sich führte ${ }^{136}$. Arnalls Tangerer Komplizen waren Eugene Chappory - Mitglied der britischen Handelskammer von Tanger, Eigentümer des Cecil Hotels und Tangerer Agent der Royal Mail ${ }^{137}$ - sowie Roque de Sots Lyons. Letzterer war Aktionär des Anglo-Moroccan Mining Syndicate, ehemaliger Leiter der britischen Post von Tanger und nunmehriger Grundstücksmakler ${ }^{138}$. John Arnalls Ehefrau Gertrude war Ende 1924 zusammen mit Captain C.S.B. Mundey und dem Apotheker Ernest Florentine Bonich an der Lieferung von Medikamenten und Hilfsgütern der British Red Crescent Society ins Rif beteiligt ${ }^{139}$. Im Juli 1925 lieferte Captain R.S.B. Beckett, Teilhaber der Tangier Overland Motor Company, zusammen mit Gertrude Arnall Ersatzreifen für Abdelkrims Autos und große Mengen Telefonleitungen ins Rif $^{140}$.

Die Untätigkeit der Sicherheitseinheit Tabor de police, die unter französischem Kommando stand, erklärte sich nach Ansicht des amerikanischen Militärattachés von Madrid, der Tanger vom 21. bis zum 25. Juni 1925 einen Be-

${ }^{133}$ CADN Madrid C263: CG Tanger an MAE, 2.4.1922; CADN Tanger A427: Renseignements du drogmanat, 31.3.1922.

${ }^{134}$ PRO-MUN 4, 6142: Embajada de Londres an FO, 10.7.1922.

${ }^{135}$ CADN Tanger A427: Centre de renseignements extérieurs du Maroc, Tanger, Note, 22.9.1922.

${ }^{136}$ SHAT 3H102: Ambassade de Madrid an MG, EMA, 2e bureau, 27.3.1924; CADN Madrid C275: Ambassade de Madrid an MG, EMA, $2^{\mathrm{e}}$ bureau, 4.4.1924.

${ }^{137}$ CADN Tanger B30: RG Rabat an CG Tanger, 26.9.1924; SHAT 3H102: Ambassade de Madrid an MG, EMA, $2{ }^{e}$ bureau, 27.3.1924; PRO-FO 368, 1332, 152703: Bericht »British Chamber of Commerce, Tangier, $1915 \%$.

${ }^{138}$ PRO-BT 31, 19288, 108057: Bericht $)$ Summary of Share Capital and Shares of AngloMoroccan Mining Syndicate Limited«, 31.12.1921; SHAT 3H102: Ambassade de Madrid an MG, EMA, $2^{\circledR}$ bureau, 27.3.1924.

${ }_{139}$ ADMAE Maroc 135, 190: CG Tanger an MAE, 2.2.1926; ADMAE Maroc 135, 116: Tabor de police $\mathrm{N}^{\circ}$ 1, Information, 11.1.1926; PRO-FO 371, 11079, 39, 43: Gertrude Arnall an CG Tangier, 19.7.1925. Siehe auch Kapitel 3, S. 74.

${ }^{140}$ CADN Tanger C39: Tabor de police $\mathrm{N}^{\circ} 1$, Note, 15.7.1925; CADN Madrid C263: CG Tanger an MAE, 1.8.1925; PRO-FO 371, 11078, 39, 128: Embajada de Londres an FO, 20.7.1925; PRO-FO 371, 11079, 39, 41: CG Tangier an FO, 30.7.1925. 
such abstattete, durch eine stillschweigende Übereinkunft zwischen Franzosen und Rifkabylen. Dafür, daß die Konvois die Tangerzone passieren konnten, drohte der Stadt im Gegenzug keine Gefahr eines Angriffs ${ }^{141}$.

Die Ende 1924 nach dem Fall von Chichaouen eingerichtete Primo-de-Rivera-Linie hatte allerdings zur Folge, daß Tanger immer mehr abgeriegelt wurde. Nachschublieferungen ins Rif auch aus dem Chleuh-Distrikt, aus Arzila und Larache, aus dem Rio-Martín-Tal oder Tetuan fielen nach und nach aus. Bis zum Sommer 1925 verstanden es die Spanier, ihren Blockadegürtel immer enger zu ziehen. Primo de Rivera verfolgte den Plan, die Rifkabylen auszuhungern ${ }^{142}$. Anfang $1926 \mathrm{kam}$ der aus der internationalen Zone stammende Nachschub praktisch zum Erliegen ${ }^{143}$.

\subsection{Charles Gardiner und der Nachschub aus Gibraltar}

Kontakte der Rifkabylen zur britischen Kronkolonie Gibraltar auf der iberischen Halbinsel gab es schon länger. In den 1890er Jahren kaperten Rifpiraten gelegentlich aus Gibraltar kommende Schmuggelschiffe, oder sie betrieben mit ihnen gemeinsamen Waffenhandel ${ }^{144}$. Es war bekannt, daß die Tosso-Brüder die Berber von Kebdana östlich von Melilla belieferten ${ }^{145}$. Von Gibraltar aus wurde Scherif Mohammed Ameziane während seines Rif-Aufstandes im Jahre 1911 mit Waffen versorgt ${ }^{146}$.

Direkte Kontakte zwischen Gibraltar und Abdelkrim bestanden seit $1921^{147}$. Der Freihafen entwickelte sich zu einem wichtigen Schmuggelzentrum für die Rifkabylen ${ }^{148}$. Spanischen Quellen zufolge sollen der Honorarkonsul von Rumänien und Siam Henry J. King und sein Kompagnon Licudi zusammen mit John Bevan, dem Vertreter der Bergbaufirma J.J. Fordham \& Co., Nachschub-

${ }^{141}$ PRO-FO 371, 11079, 39, 139: Embassy of Madrid an FO, 18.7.1925 mit einem beigefügten Bericht des US-amerikanischen Militärattachés »C.B.H.« o.D. [Juli 1925].

${ }^{142}$ SHAT 3H102: EMA, $2^{\mathrm{e}}$ bureau, Renseignement, 25.8.1925.

${ }^{143}$ CADN Londres C528: MAE an Ambassade de Londres, 30.8.1926 mit Bezug auf einen Bericht von Capitaine Schmidt; CADN Tanger C37: Bericht »Ravitaillement du Riff par Tanger «, 19.1.1926.

${ }^{144}$ CADN Tanger A396: Consulat de Tétouan an Chargé d'affaires de Tanger, 10.11.1896; AYACHE, Les origines, S. $107 \mathrm{f}$.

${ }^{145}$ DuNN, European Connexion, S. 243.

${ }^{146}$ MONTORO OBRERO, Tráfico de armas, S. 253.

${ }^{147}$ CADN Madrid C271: MAE an Ambassade de Madrid, 26.9.1921 mit Bezug auf Aussagen von Daniel Bourmancé-Say, 18.9.1921.

${ }^{148}$ MONTORO OBRERO, Tráfico de armas, S. 257. 
lieferungen organisiert haben ${ }^{149}$. Der britische Gouverneur von Gibraltar bezweifelte jedoch derartige Berichte, und Bevans Chef James Fordham gab in London seine Garantie dafür, daß seine Firma keine Waffengeschäfte mit dem Rif betreibe ${ }^{150}$. Allerdings kann als gesichert gelten, daß Bevan 1923 an der Entwicklung des Telefonnetzes im Rif beteiligt war ${ }^{151}$. Auch der Brite Louis de La Garde brach mit einem Schmuggelschiff des Spaniers Pedro Conde alias El buzo ins Rif auf, um Waffen zu verkaufen. In der Folgezeit intensivierte die spanische Marine ihre Blockadeversuche an der Rifküste ${ }^{152}$.

Weitere Schmuggler aus Gibraltar waren Raphael Berto, ein Mann namens Soreya, der Malteser Kerouan und die Lamato-Brüder. Im Juni 1924 ließ Berto in Malaga einen Dampfer mit einer Ladung Schwefel und Blei für das Rif beladen. Im gleichen Monat versuchten die Lamatos von Gibraltar aus immer wieder, mit kleinen Booten, die mit Pulver, Pistolen und Munition beladen waren, die Rifküste zu erreichen ${ }^{153}$. Marschall Lyautey benannte auch die Brüder Favio sowie Benhimol und Benzaqem als Vermittler für Waffenschmuggel in Gibraltar ${ }^{154}$. Im portugiesischen Porto wurden Waffen von englischen auf spanische Schiffe umgeladen und falsch deklariert ${ }^{155}$. Die Helfer der britischen Schmuggler kamen mit ihren schnellen kleinen Schiffen aus Italien, Algerien, Spanien oder Malta. Auch Deutsche und Russen waren darunter ${ }^{156}$. Auguste Terrier vom Comité de l'Afrique française, der gute Kontakte zu den französischen Behörden Marokkos hatte, bezeichnete die Schmuggler in einer Artikelserie als $»$ Bruderschaft der Rifküste ${ }^{157}$.

${ }^{149}$ PRO-FO 371, 9470, 44, 78: Embajada de Londres an FO, 9.10.1923; PRO-FO 371, 10582, 101, 141: Embassy of Madrid an FO, 12.11 .1924 mit dem beiliegenden Brief Presidency of the Military Directorate, Office for Morocco an Embassy of Madrid, 6.11.1924.

${ }^{150}$ PRO-CO 91, 482, 58655: Governor of Gibraltar an CO, 24.11.1923; PRO-FO 371, 9470, 44, 173: New Scotland Yard an FO, 21.11.1923.

${ }^{151}$ ADMAE Maroc 133, 100: Bericht »La question riffaine vue de la méditerranée« von $\mathrm{Da}$ niel Bourmancé-Say, 28.5.1925; WARD PRICE, Extra-Special Correspondent, S. 172 (bezieht sich auf Aussagen von Si M'hammed); SHAT 3H134: Ambassade de Madrid, Attaché militaire an MG, EMA, $2^{\mathfrak{e}}$ bureau, 27.3.1924. Siehe Kapitel 4, S. $118 \mathrm{f}$.

152 BEVAN, Spain and Morocco II, 23.10.1923.

${ }^{153}$ CADN Londres C519: MAE an Ambassade de Londres, 27.10.1924 mit dem Bericht "Agissements anglais au Maroc«; CADN Maroc DAI 194: Bericht »Note au sujet du ravitaillement en armes et munitions du Rif par mer«, 30.5.1925.

${ }^{154}$ SHAT 3H1558: Louis-Hubert Lyautey an Commandant de la région de Fès, 11.7.1924.

${ }^{155}$ ADMAE Maroc 220, 93: Bericht "Contrebande d'armes de provenance anglaise«, 15.6.1925.

${ }^{156}$ MONTORO Obrero, Tráfico de armas, S. 257; DuMAS, Abd-el-Krim, S. 44; LOZE, Chez eux, 12.4.1926.

${ }_{157}$ TERRIER, Les »Frères de la côte« 1925, S. 548-549, S. 652-657; DERS., Les »Frères de la côte« 1926, S. 38-45, S. 68-71, S. 111-114, S. 176-179, S. 299-309; DERS., Les »Frères de la côte« 1927, S. 46f. Vgl. DAOUD, Abdelkrim, S. 98. 
Abdelkrims wichtigster Verbindungsmann nach Gibraltar war sein Marineminister Sibbera ${ }^{158}$. Er war ein Seemann mit Piratenerfahrung und galt als erfahrener Schmuggler. 1896 bereits war Sibbera von spanischer Seite gefangengenommen worden, als er ein spanisches Schiff hatte entern wollen. 1911 wurde er in Tanger wegen Schmuggelhandels verhaftet ${ }^{159}$. Sibbera zählte kurz nach der Errichtung der spanischen Einflußzone in Marokko noch zu den Anführern der "Freunde Spaniens« unter den Beqqioua. Er kassierte nicht nur Pensionszahlungen in Höhe von monatlich 500 Peseten, sondern soll General Silvestre Anfang 1921 sogar die Landung bei Morro Nuevo in Aussicht gestellt haben. Nachdem sich Sibbera im März 1921 zusammen mit vier weiteren Beqqioua mit Hochkommissar Dámaso Berenguer y Fusté getroffen hatte, wurde er von Abdelkrim ultimativ aufgefordert, die Seiten zu wechseln ${ }^{160}$. Sein Schwager Si Abdelkrim ben el Haj Ali Luh bildete in Tanger die andere Stütze des Schmuggels ${ }^{161}$. Der Chefaufkäufer für Munition war Mohammed Ghomari ${ }^{162}$. Die Anlegestellen für Schmuggelschiffe lagen an der BeqqiouaKüste (Bou Sekour, Marsa Beqqioua und Iger Aïch westlich von Morro Nuevo $^{163}$ ) sowie vor Ajdir ${ }^{164}$, an der Beni-Bou-Ifrah-Küste ${ }^{165}$ und an der Mündung des Oued Lau ${ }^{166}$.

Französischen Berichten zufolge nahm der Zufluß an Waffen, die an der Rifküste entladen wurden, auch 1925 nicht ab. Ein italienischer Deserteur aus der französischen Fremdenlegion beobachtete im Februar 1925 die Lieferung von Maschinengewehren ${ }^{167}$. Im gleichen Monat sollen 3000 Mauser-Geweh-

${ }^{158}$ CADN Tanger B30: RG Rabat an CG Tanger, 26.9.1924; SHAT 3H1557: Territoire de Taza, SR, Renseignements, 10.9.1924.

${ }^{159}$ GHIRELLL, Monografia, S. $81 \mathrm{f}$.

${ }^{160}$ PENNELL, The Responsibility, S. 78; DERS., A Country, S. 48f., S. 73f.; AYACHE, Les origines, S. 154; DERS., La Guerre du Rif, S. 174 u. S. 174, Anm. 29; PANDO, Historia secreta, S. $102 f$.

${ }^{161}$ CADN Tanger B30: RG Rabat an CG Tanger, 26.9.1924; SHAT 3H1557: Territoire de Taza, SR, Renseignements, 10.9.1924.

${ }_{162}$ WOOLMAN, Rebels in the Rif, S. 148.

${ }^{163}$ SHAT 3H1103: Contrôle civil de Taourirt, Bulletin de renseignements, 13.9.1924; SHAT 3H1557: Contrôle civil de Taourirt, Bulletin de renseignements, 22.10.1924; SHAT 3H146: Consulado de Oujda an Alto comisario de Tetuan, 9.9.1924; SHAT 3H1557: Territoire de Taza, SR, Renseignements, 10.9.1924; SHAT 3H1557: Région de Fès, SR, Bulletin de renseignements, 9.5.1924; CADN Maroc DAI 194: Bericht »Note au sujet du ravitaillement en armes et munitions du Rif par mer«, 30.5.1925; ADMAE Maroc 220, 145: MG, EMA an MAE, 2.7.1925.

${ }^{104}$ RUE, News, S. 270; FLEMING, Primo de Rivera and Abd-el-Krim, S. 226.

${ }^{165}$ SHEEAN, My Meeting, S. 880; ADMAE Maroc 99, 244: EMA, $2^{\mathrm{e}}$ bureau, Bericht $\gg$ Renseignements sur Abd el Krim et sur la contrebande d'armes au Maroc«, 2.9.1925.

${ }_{166}$ AN 475 AP 193: Bericht "La situation au Maroc en 1925-1926, La guerre du Rif, le passé, le présent, l'avenir«, 18.2.1926; TERRIER, Les »Frères de la cóte« 1925, S. 549, S. 652.

${ }^{167}$ CADN Madrid C263: MAE an Ambassade de Madrid, 4.9.1925 mit Bezug auf Aussagen von Antonio Palmeri. 
re, zehn leichte Feldkanonen, zehn Munitionskisten für Artillerie und zehn Kisten Motorenersatzteile in Richtung Rif geschickt worden $\operatorname{sein}^{168}$. Ein englisches Schiff, das ebenfalls im Februar 1925 aus Gibraltar kommend an der Rifküste anlegte, hatte 2000 Lebel-Gewehre an Bord ${ }^{169}$.

Die spanische Marine hatte ihre Bewachung der Küste zwar seit Ende 1924 verstärkt, der Erfolg hielt sich aber in Grenzen ${ }^{170}$. Der amerikanische Journalist Vincent Sheean wurde während seines Rifbesuches im Januar 1925 von einem Hafen an der Beni-Bou-Ifrah-Küste weiter westlich nach Oued Lau verschifft, wobei zwei spanischen Marinebooten mühelos ausgewichen werden konnte. Sein Bootsführer war ein im Schmuggel erfahrener Einheimischer, den alle nur »das Schwert« (ital. la spada) nannten. Es ist kaum anzunehmen, daß Abdelkrim seinen Gast diese Reise hätte antreten lassen, wenn für ihn eine größere Gefahr durch spanische Schiffe bestanden hätte ${ }^{171}$.

Die Diplomaten im britischen Außenministerium wollten die spanischen Vorwürfe, daß das Rif mit aus Gibraltar stammenden Schiffen versorgt würde, zunächst nicht glauben und den Schwarzen Peter zurückschieben. Sie gingen davon aus, daß die Riftruppen den Großteil ihrer Ausrüstung der spanischen Marokkoarmee entwendet hatten ${ }^{172}$. Dennoch gab sich Gibraltars Gouverneur C.C. Munro wachsam und beteuerte, jeden Versuch des Schmuggelhandels mit dem Rif zu unterbinden ${ }^{173}$. In einem Gespräch mit dem französischen Botschafter in London, der die Beteiligung von Briten am Waffenhandel mit dem Rif kritisierte, gab sich der britische Staatssekretär Sir Eyre Crowe machtlos. Da die englischen Lieferanten Abdelkrims die Waffen in Kenntnis des britischen Rechts auf nicht-englischen Schiffen liefern würden und Verladung sowie Verkauf der Fracht außerhalb des britischen Territoriums erfolge, könne die britische Regierung nicht dagegen einschreiten ${ }^{174}$. Im März 1926 betonte ein Bericht des Außenministeriums, daß Untersuchungen keinen Beweis dafür erbracht hätten, daß es in Gibraltar Waffengeschäfte mit dem Rif gegeben hätte t75. $^{17}$.

${ }^{168}$ ADMAE Maroc 220, 84: EMA, $2^{e}$ bureau, Bericht »Matériel de guerre pour le Rif«, 4.6.1925.

${ }^{169}$ CADN Maroc DAI 194: Bericht »Note au sujet du ravitaillement en armes et munitions du Rif par mer«, 30.5.1925; SHAT 3H134: Renseignements, 11.2.1925; Die Lage in Marokko, in: Kölnische Zeitung, 2.6.1925.

${ }^{170}$ MONTORO OBRERO, Tráfico de armas, S. 257f.

${ }^{171}$ SHEEAN, Personal History, S. 115 f; DERS., Riff Laughs, 13.2.1925; DERS., An American, S. 216f.; DERS., My Meeting, S. 880; WOOLMAN, Rebels in the Rif, S. 155.

${ }^{17}$ PRO-FO 371, 9470, 44, 76: Minute, 12.10.1923.

${ }^{173}$ PRO-CO 91, 482, 58655: Governor of Gibraltar an FO, 24.11.1923.

${ }^{174}$ ADMAE Maroc 219, 188: Ambassade de Londres an MAE, 14.1.1925.

${ }^{175}$ CADN Londres C520: FO an Embassy of France, 11.3.1926. 
Ganz anders sah dies der dortige französische Konsul. Da im Freihafen wegen einer fehlenden Zollverwaltung keinerlei Überwachung oder Kontrolle der Schiffe erfolgte, konnten Lieferungen problemlos und unbeobachtet umgeladen werden ${ }^{176}$. In seinen Erinnerungen schrieb Abdelkrim über die Engländer: "In Massen brachten sie uns von Gibraltar und vom Kap Moro her Munition und Salz « ${ }^{177}$. »Times«-Korrespondent Walter Harris, der in einem Artikel vom 11. September 1924 noch jegliche britische Unterstützung Abdelkrims in Abrede gestellt hatte ${ }^{178}$, mußte nur wenige Tage später seinem Londoner Chef Harold Williams kleinlaut eingestehen, daß er sich geirrt hatte, denn Abdelkrim hatte ihm umfangreiches Informationsmaterial über die Verwicklungen von Briten zugesandt. Sein Fazit lautete nun, daß der Waffenhandel praktisch in britischer Hand lag $^{179}$.

Einer der agilsten Waffenschmuggler war der Engländer Captain Charles Alfred Percy Gardiner. In einer Artikelserie für die Zeitung »lllustrated Sunday Herald gab er an, nach einem bewegten Seefahrerleben sowohl im Burenkrieg als auch im russisch-japanischen Krieg gekämpft zu haben, ehe er während des Ersten Weltkrieges Kommandant eines als Handelsschiff getarnten Kriegsschiffes gewesen sei $^{180}$. Er lebte mit seiner Ehefrau Ina in London $^{181} .1919$ hatte Gardiner die Firma Gardiner Shipbuilding and Engineering Company gegründet und dort als Schiffskonstrukteur und Ingenieur fungiert $^{182}$. Im Februar 1921 konnte Gardiner wegen finanzieller Schwierigkeiten

${ }^{176}$ CADN Londres C520: Consul de Gibraltar an MAE, 26.4.1926.

${ }^{177}$ ABDELKRIM, Memoiren, S. 98.

${ }^{178}$ Walter B. HARRIS, The Moroccan Campaign. Stories of British Aid for Rifis. Propaganda Tales, in: Times, 11.9.1924.

${ }^{179}$ TNLA, BNS, 1, Williams: Walter Harris an Harold Williams, 18.9.1924.

${ }^{180}$ Charles A.P. GARDINER, My Own Story. Captain Gardiner's First Sensations Under Sea, in: Illustrated Sunday Herald, 7.6.1925; DERS., Kidnapping a Crew for a 2000 -Mile Trip, in: Illustrated Sunday Herald, 14.6.1925; DERS., Grand Guignol Drama Under Water, in: Illustrated Sunday Herald, 21.6.1925; DERS., Kitchener's Wire About the Wild Men, in: Illustrated Sunday Herald, 28.6.1925; DERS., My Arrest for Minefield Disaster, in: Illustrated Sunday Herald, 5.7.1925; DERS., My Under-Sea Battle with an Octopus, in: Illustrated Sunday Herald, 12.7.1925; DERS., Mystery Ship Thrills in the Great War, in: Illustrated Sunday Herald, 19.7.1925.

${ }^{181}$ CADN Tanger C39: Tabor de police $\mathrm{N}^{\circ} 1$, Note de renseignements, 17.11.1925; APP BA 1678: Bericht "A.S. du capitaine Gardiner et de Hacklaender qui se livreraient au trafic des armes«, 27.4.1925; AN F7, 14980: Bericht "Notice sur Gardiner« o.D. (1927); PRO-FO 371, 10581, 783, 36: CO an FO, 21.7.1924. Zakya Daoud benutzt für Gardiner fälschlicherweise den Vornamen »Robert«. Hier liegt eine Verwechslung mit Robert Gordon-Canning vor [DAOUD, Abdelkrim, S. 13, S. 166, passim]. Guadelupe Montoro Obrero verwandelt Gardiner in einen Holländer (»el peligroso contrabandista holandés Gardiner«) [MONTORO OBRERO, Tráfico de armas, S. 257].

${ }_{182}$ PRO-BT 31, 25262, 160911: Mappe wGardiner Shipbuilding and Engineering Company, 1919«; Man of Many Adventures, in: Daily Mail, 21.5.1925; BOUTBOUQALT, La Guerre du Rif, S. 33; Une nouvelle république dans l'Afrique du Nord: Le Rif, in: Matin, 19.7.1924; AN F7, 13413: Bericht „Déclaration de M. Deboe«, 30.7.1925. 
den Auftrag für den Bau von vier Tankschiffen nicht mehr erfüllen. Seither war er in Waffenlieferungen nach Griechenland verwickelt, und er arbeitete als Geschäftsführer der British United Shipbuilding Corporation ${ }^{183}$.

Gardiner kam Anfang 1923 mit den Rifkabylen in Kontakt. Seit Ende 1922 hielten sich Abdelkrims Bruder Si M'hammed und dessen Begleiter Si Mohammed Mohammedine Hitmi in Paris auf, um politische und wirtschaftliche Verhandlungen zu führen. Ein weiterer Grund des Besuchs war, daß die Artillerie-Munition im Rif immer knapper wurde ${ }^{184}$. Zudem machten sich Abdelkrim und sein Bruder Sorgen um die Zukunft. Da sie noch lang andauernde Kämpfe um die Unabhängigkeit befürchteten, wollten sie die militärische Ausstattung der Rifarmee unbedingt weiter modernisieren ${ }^{185}$. Zunächst kamen die Rifgesandten mit »einer Bande von Betrügern ${ }^{186}$ in Kontakt, die Schmuggelerfahrung mit unterschiedlichsten Ländern aufzuweisen hatte. Die Franzosen Henri François Moulis, Marcel Collin und ihre Gruppe waren jedoch nicht in der Lage, binnen acht Wochen Kriegsmaterial im Wert von 20 Millionen Francs an das Rif zu liefern ${ }^{187}$. Im Dezember 1923 sollten Moulis und Collin wegen eines weiteren geplanten Waffengeschäftes mit Serbien von der französischen Polizei verhaftet werden ${ }^{188}$.

Ein deutscher Geschäftsmann, der Moulis und Collins kannte, vermittelte den Kontakt Si M'hammeds zu Charles Gardiner. Es handelte sich um Karl Hermann Hackländer aus Wermelskirchen, der mit dem Briten befreundet war $^{189}$. Hackländer war ein honoriger Bürger, der im gesellschaftlichen, politischen und wirtschaftlichen Leben seiner Heimatstadt eine wichtige Rolle spielte. Das Mitglied der Bergischen Industrie- und Handelskammer war Inhaber der Plüschweberei und Deckenfabrik Hackländer \& Co. und besaß zusätzliche Webefabriken in Spanien. Hackländer war zudem der Mitbegründer der Wermelskirchener Ortsgruppen der Deutschen Demokratischen Partei sowie des Freiwirtschaftsbundes ${ }^{190}$.

${ }^{183}$ PRO-FO 371, 9474, 2275, 208: Embassy of Paris an FO, 29.5.1923; ADMAE Maroc 111, 46: Charles Gardiner an Si M'hammed, 30.4.1923.

${ }^{184}$ ADMAE Maroc 133, 117: Bericht „Notes et remarques» von Daniel Bourmance-Say.

${ }^{185}$ Maurice-Ivan SICARD, Doriot et la Guerre du Rif. Études et documents, Paris 1943, S. 143 mit Bezug auf ein Zitat von Si M'hammed.

186 SUEIRO SEOANE, España, S. $25 f$.

${ }^{187}$ Charles Gardiner an Messrs Moulis et Cie., 21.4.1923, in: DUNET, La sanglante aventure, S. 93-96, S. $93 \mathrm{f}$.

${ }^{183}$ ADMAE 219, 171: Embajada de Paris an MAE, 31.12.1924; APP BA 1678: Bericht "A.S. de la contrebande d'armes à destination du Riff«, 24.2.1925.

${ }^{189}$ ADMAE Maroc 133, 15: Notice o.D. [August 1925]; CADN Londres C519: MAE an Ambassade de Londres, 26.5.1924; ADMAE Maroc 133, 136: Embajada de Paris an MAE, 30.12.1924; PRO-FO 371, 9474, 2275, 121: Embajada de Londres an FO, 18.6.1923.

${ }^{190}$ APP BA 1678: Bericht wA.S. de la contrebande d'armes à destination du Riff/, 24.2.1925; AN F7, 13413: Bericht »Déclaration de M. Deboe«, 30.7.1925; Mitteilungen des Stadtarchivs Wermelskirchen, 7.10.1998, 29.10.1998 und 19.11.1998; Mitteilung des Bergi- 
Am 30. April 1923 unterzeichnete Gardiner in Paris einen umfassenden Kontrakt über Nutzungsrechte innerhalb des Rifs. Er wurde sogar zum »Generalbevollmächtigten für auswärtige Beziehungen« ernannt. $\mathrm{Zu}$ den Vertragspapieren gehörte eine lange Bestelliste für Kriegsmaterial aller Art, das er bis zum 30. Oktober 1923 auszuliefern hatte. Auf ihr sind 30000 Gewehre mit jeweils 1000 Schuß Munition, zwei Millionen Schuß Munition für Maschinengewehre, Artilleriegeschütze mit Granaten, vier Jagdflugzeuge, acht Bomber-Flugzeuge, ein Unterseeboot mit Besatzung, U-Boot-Jagdschiffe, Ausrüstung für das Telefonnetz, Handgranaten, Mörser, Feldstecher, Leuchtraketen und vieles mehr aufgeführt. Die Liste läßt auf den Plan einer grundlegenden Modernisierung der Rifarmee und des Feldtelefonnetzes schließen ${ }^{191}$. Abdelkrim versuchte ebenso - noch vor der ersten wirklichen >Gasschlacht zi Azza im Juni 1923 -, seinerseits an Gasbomben zu gelangen. Er orderte 50 nicht näher spezifizierte Gasgranaten. Gardiner konnte diese Bestellung allerdings nicht realisieren ${ }^{192}$. Auch wenn der Erwerb einer derartigen Menge an militärischem Gerät auf den ersten Blick illusorisch erscheinen mag - Abdelkrim war durchaus in der Lage, das meiste zu finanzieren. Gerade erst hatte er Ende Januar 1923 für die Freilassung spanischer Kriegsgefangener über vier Millionen Peseten erhalten ${ }^{193}$.

Charles Gardiners Bemühen, Si M'hammeds Bestelliste abzuarbeiten, führte ihn auch nach Berlin. Anfang September 1923 tauchte er in Begleitung eines deutschen Partners - dies kann nur Karl Hackländer gewesen sein - im Auswärtigen Amt auf und bat die entsetzten Diplomaten darum, »ihm behilflich zu sein, in Deutschland etwa noch versteckt gehaltene Unterseeboote für die RiffRepublik anzukaufen«. Als dies klar verneint und jede Vermittlung abgelehnt wurde, sagte Gardiner, daß er sich nun an die russische Vertretung wenden wolle, während sein deutscher Partner sich mit der Rüstungsfirma Krupp in Verbindung setzen werde. Dort versicherte man dem Auswärtigen Amt je-

schen Geschichtsvereins, 22.10.1998; KHARCHICH, La France, S. 159-163; MADARIAGA, España y el Rif, S. 537; GIORGI-MIGNOT, Les milieux, S. 84; WOLF, Les secrets, S. 123f.; HARRIS, Captain Canning and Abd-el-Krim, 30.1.1926; Jacques LADREIT DE LACHARRIERE, Intrigues riffaines, in: Revue indigène 203-204 (1925) S. 232-236, S. 234f.; Ein Geheimdokument über Marokko, in: Weser-Zeitung, 11.12.1925; Zur Geschichte der Webkunst in Wermelskirchen bis zur Jahrhundertwende, in: Bergische Tageszeitung, 31.10.1942; Otto FISCHER, Wermelskirchen. Die Stadt von über 1000 Jahren und seine (sic!) Industrie, Wermelskirchen 1926, S. 80f.; Thomas WINTGEN, Wermelskirchen in der Weimarer Republik. Die Jahre 1918 bis 1932 im Spiegel der Lokalpresse, Wermelskirchen 1993 (Wermelskirchen, Beiträge zu unserer Geschichte, 6), S. 155.

${ }^{191}$ ADMAE Maroc 111, 25: Vertrag Rifregierung und Charles Gardiner, 30.4.1923. Vgl. WOOLMAN, Rebels in the Rif, S. 127; MADARIAGA, España y el Rif, S. 535; ESPAÑA, La actuación, S. 294; TAHTAH, Pragmatisme 1995, S. 104; KHARCHICH, La France, S. 454f.

${ }^{192}$ BALFOUR, Deadly Embrace, S. $191 \mathrm{f}$.

${ }^{193}$ ÁlvareZ, The Betrothed of Death 2001, S. 85; PenNell, A Country, S. 114. 
doch, daß man nicht mit Gardiner verhandeln werde ${ }^{194}$. Die deutsche Botschaft Madrid warnte Berlin, wdass Herr Gardiner ein nicht ernst zu nehmender und mit Vorsicht zu behandelnder Abenteurer« sei ${ }^{195}$.

Da der Brite den Oktobertermin für die erste Schiffslieferung an Waffen nicht einhalten konnte, bat er Abdelkrim um eine Verlängerung der Frist ${ }^{196}$. Im Oktober 1923 kaufte Gardiner die "Sylvia«, ein Schiff von 40 Tonnen Gewicht und $80 \mathrm{FuB}$ Länge. Er hatte den Auftrag, dieses Boot samt Funkanlage zur Rifküste zu befördern. Wegen der schlechten Wetterverhältnisse zu dieser Jahreszeit beschloß Gardiner, die »Sylvia« mit ihrer zehnköpfigen Mannschaft quer durch Frankreich über Flüsse und Kanäle zum Mittelmeer zu führen ${ }^{197}$. Zunächst fuhr er über Cherbourg nach Den Haag, dann über Le Havre nach Paris, wo er das Boot Anfang November 1923 für einen fünfwöchigen Aufenthalt am Quai de Tokyo anlegen ließ ${ }^{198}$.

Dort stieg El Hadi ben Dadi ben Mohammed hinzu, der Gardiner zur Rifküste geleiten sollte. Im Oktober 1923 hatte er sich nach Frankreich begeben. In Saint-Étienne wurde er für kurze Zeit zur Tarnung als Arbeiter in der Steinkohlehandlung eines Mustafa beschäftigt, ehe er sich nach Paris aufmachte ${ }^{199}$. Neben El Hadi ben Dadi ergänzten der schottische Schiffsführer Captain MacLean, Gardiners Ehefrau Ina, Roy Calvert von der am Rifbergbau interessierten International Oil Company, die Seeleute Riding, Mowart, Clevlyn und G.L. Mills sowie Gardiners Geschäftspartner Lord Teynham die Mannschaft der »Sylvia ${ }^{200}$.

Am 15. oder 16. Dezember 1923 verließ die »Sylvia Paris in Richtung Marseille. Die Fahrt durch das winterliche Frankreich entwickelte sich nicht nur wegen der Verfolgung durch spanische Geheimagenten chaotisch. Wegen der Brücken mußten ein Mast und das Deckhaus gekürzt werden, Kanäle waren vereist, die Saône fuihrte Hochwasser und in Avignon brach Feuer an Bord

\footnotetext{
194 PA-AA R72063: Geheimvermerk, 8.9.1923. Vgl. KuNZ, MŨLLER, Giftgas, S. 104.

${ }^{195}$ PA-AA R72063: Botschaft Madrid an AA, 30.10.1923.

${ }^{16}$ AN F7, 13413: Bericht »Déclaration de M. Deboe«, 30.7.1925.

${ }^{197}$ GARDINER, Ambassador, 26.7.1925; SHAT 3H1557: Contrôle civil de Taourirt, Bulletin de renseignements, 22.10.1924.

${ }^{198}$ ADMAE Maroc 219, 171: Embajada de Paris an MAE, 31.12.1924; PRO-FO 371, 10583, 783, 7: Embajada de Londres an FO, 24.5.1924.

${ }^{199}$ GABRIELLI, Abd-el-Krim, S. 13f.; DAOUD, Abdelkrim, S. 165; SHAT 3H1557: Contrôle civil de Taourirt, Bulletin de renseignements, 22.10.1924; 3H135: EMA, $2^{e}$ bureau, SR, Renseignements, 30.12.1926.

${ }^{200}$ GARDINER, Ambassador, 26.7.1925; Man of Many Wars, in: Al-Moghreb al Aksa \& Tangier Gazette, 6.6.1925; PRO-FO 371, 9470, 44, 91, 136: Embajada de Londres an FO, 17.10.1923 und 26.10.1923; PRO-CO, 91, 482, 52716: $\mathrm{CO}$ an Governor of Gibraltar, 31.10.1923; PRO-FO 371, 10583, 783, 18: Embajada de Londres an FO, 14.6.1924; PROFO 371, 10583, 783, 36: CO an FO, 21.7.1924 mit dem beigefügten Brief G.L. Mills an Captain of the Port, Gibraltar, 9.4.1924.
} 
aus $^{201}$. Da die Gardiners für politische Verhandlungen im Namen Abdelkrims nach Paris zurückgerufen wurden, lag es an Captain MacLean, die arg in Mitleidenschaft gezogene "Sylvia« zur Rifküste zu navigieren. Er entschied sich dafür, die im Mittelmeer auf ihn lauernden spanischen Marineschiffe zu bluffen und an der iberischen Küste entlang in Richtung Süden zu fahren. Nachdem im spanischen Hafen von Almeria sogar noch der Schiffsmotor repariert werden mußte, ging die Fahrt weiter. El Hadi ben Dadi entpuppte sich als wenig geeigneter Seemann, der nicht einmal in der Lage war, das Ziel der Reise - die Bucht von Alhucemas - zu erkennen. MacLean fand sie dennoch und lief am 14. Februar 1924 ein. Wo die "Sylvia« ihre Ladung an Bord genommen hatte, ist nicht bekannt. Sie bestand aus drei Kisten mit Waffen, Decken, Feldtelefonen und Telegrafenstationen ${ }^{202}$.

Am 10. März 1924 stieg das Ehepaar Gardiner im Grand Hotel von Gibraltar ab. Per Funk benachrichtigten sie Captain MacLean, sie auf seiner Rückfahrt nach Großbritannien, wo neuer Nachschub wartete, abzuholen. Die "Sylvia« lief am 20. März 1924 im Freihafen ein. Die aus London vorgewarnten Behörden bewachten jeden Schritt der Besatzung. Vier Mann verließen das Schiff. Unter ihnen befand sich der Schiffsingenieur G.L. Mills, der in einem Brief an den Hafenmeister vom 9. April 1924 die Schmuggelgeschäfte mit dem Rif bestätigte. Ferner warf er Gardiner vor, den spanischen Funkverkehr abgehört und Abdelkrim übermittelt zu haben ${ }^{203}$. Eine Reaktion blieb jedoch aus. Kurz zuvor war die »Sylvia« am 29. März 1924 in Richtung London und Liverpool ausgelaufen ${ }^{204}$. Am 6. April 1924 kehrte sie nach Gibraltar zurück, und vier Tage später brach sie, ohne daß die Behörden von Gibraltar eingeschritten wären, mit Charles und Ina Gardiner an Bord in Richtung Rif auf. Diesmal waren die Spanier wachsamer. Als die Rifküste angesteuert wurde, griffen spanische Flugzeuge die »Sylvia« in der Bucht von Alhucemas an, verfehlten ihr Ziel allerdings ${ }^{205}$.

${ }^{201}$ Ina GARDINER, Peril of Floods, in: Illustrated Sunday Herald, 26.7.1925; ADMAE Maroc 219, 171: Embajada de Paris an MAE, 31.12.1924; CADN Maroc DAI 194: Bericht »Note au sujet du ravitaillement en armes et munitions du Rif par mer«, 30.5.1925; SHAT 3H1557: Contrôle civil de Taourirt, Bulletin de renseignements, 22.10.1924.

${ }^{202}$ GODED LLOPIS, Marruecos, S. 89; SHAT 3H1102: Si Mohammed Boujibar an Caîd Haddou ben Hammou, 15.2.1924; ADMAE Maroc 219, 171: Embajada de Paris an MAE, 31.12.1924.

${ }^{203}$ PRO-FO 371, 10583, 783, 36: $\mathrm{CO}$ an FO, 21.7.1924 mit dem beigefügten Brief G.L. Mills an Captain of the Port, Gibraltar, 9.4.1924; SHAT 3H1557: Contrôle civil de Taourirt, Bulletin de renseignements, 22.10.1924.

${ }^{204}$ SHAT 3H146: Dechiffrierter Brief Général en chef de Tetuan an Commandant maritime d'Alhucemas, 30.3.1924.

${ }^{205}$ PRO-FO 371, 10583, 783, 36: CO an FO, 21.7.1924; PRO-FO 371, 10583, 783, 18: Embajada de Londres an FO, 14.6.1924; GARDINER, My Escape, 2.8.1925; SUEIRO SEOANE, España, S. 29. 
Es war Gardiners erster Besuch im Rif. An diesem 10. April 1924 führte er Kisten mit Schnellfeuergewehren, Revolvern, Feldtelefonen, Decken, Munition und 3000 Litern Benzin mit sich ${ }^{206}$. Dies erfüllte die Erwartungen der Rifkabylen nicht. Auf Si Mohammed Mohammedine Hitmis Kritik, Gardiner solle lieber mehr Waffen liefern, reagierte dieser mit der Forderung nach Geld ${ }^{207}$. Abdelkrim bestand darauf, daß der Engländer zuallererst Kanonen und passende Munition ins Rif liefern müsse ${ }^{208}$.

Gardiners Versuch, die »Sylvia«, die er für 1500 Pfund gekauft hatte, für den doppelten Preis zu veräußern, machte keinen guten Eindruck. Abdelkrim kannte den ursprünglichen Kaufpreis und lehnte ab. Das Vertrauen der Rifkabylen sank immer mehr. Sie beauftragten Gardiner zwar mit einer neuen Mission zum Einkauf von Waffen. Diesmal jedoch gaben sie ihm mit Marineminister Sibbera einen Aufpasser an die Seite. In einem Spezialgürtel, den er ständig am Körper trug, führte er 500-Peseten-Scheine mit sich. Hitmi zufolge handelte es sich um die Summe von 100000 Peseten. Caïd Haddou bezifferte die Summe auf 600000 Peseten $^{209}$. Als deutliches Zeichen des Mißtrauens sollte Gardiners Ehefrau Ina als >Gast` von El Hadi ben Dadi bis zur Rückkehr der »Sylvia« im Rif verbleiben ${ }^{210}$.

Am 11. Mai 1924 legte das Schmuggelschiff wieder ab und erreichte am Morgen des 13. Mai 1924 Gibraltar. Sibbera hielt sich tagelang in der Kabine versteckt, während Gardiner über seine lokale Agentur T. Mosley \& Co. den Tank der "Sylvia« nachfüllen und Kisten von rund sechs Tonnen Gesamtgewicht verladen ließ. Captain MacLean sollte, sobald das Wetter wieder aufklarte, erneut das Rif anfahren. Mit Abdelkrim stand er über Funk ständig in Verbindung. Gardiner wartete derweil ungeduldig auf dringende Telegramme von Geschäftspartnern aus Antwerpen, die ihn zur Änderung seiner Pläne zwangen. Am 20. Mai 1924 legten Gardiner, MacLean und Sibbera mit dem Fährschiff »Noldera« nach Marseille ab, um von dort aus nach Paris weiterzufahren ${ }^{211}$.

${ }^{206}$ SHAT 3H1557: Région de Fès, SR, Bulletin de renseignements, 9.5.1924; PRO-FO 371, 10583, 783, 7: Embajada de Londres an FO, 24.5.1924.

${ }^{207}$ ADMAE Maroc 111, 1: Bericht »Renseignements donnés par El Hadj Hitmi«, 22.6.1926; BouTBOUQALT, La Guerte du Rif, S. 35.

${ }^{208}$ YoussoufI, Les institutions, S. 95; CADN Maroc DAI 198: Bericht »Déclarations de Si el Hassan Kadiri«, 26.6.1926.

${ }^{209}$ ADMAE Maroc 111, 1: Bericht »Renseignements donnés par El Hadj Hitmi«, 22.6.1926; ADMAE Maroc 199, 122: Caïd Haddou an MAE, 29.9.1924.

${ }^{210}$ GABRIELLI, Abd-el-Krim, S. 13f;; LE GUILLERME, CH. »402«, S. 95; SHAT 3H1557: Contrôle civil de Taourirt, Bulletin de renseignements, 22.10.1924.

${ }^{211}$ PRO-FO 371, 10583, 783, 36: CO an FO, 21.7.1924; PRO-FO 371, 10583, 783, 7: Embajada de Londres an FO, 24.5.1924; PRO-FO 371, 10583, 783, 18: Embajada de Londres an FO, 14.6.1924. 
Die »Sylvia« machte sich ohne Gardiner und MacLean auf den Weg ins Rif. Im Juni 1924 lief das Schiff ein weiteres Mal die Rifküste an. Mehrere französische Berichte sagen aus, daß bei Morro Nuevo 12000 bis 16000 Lebel- und Mauser-Gewehre sowie Munition und Explosivstoffe entladen wurden. Hiernach hatte Sibbera diese Gewehre von deutschen Quellen erworben ${ }^{212}$. Caïd Haddou und Pierre Fontaine zufolge hatte Gardiners deutscher Partner Karl Hackländer das Waffengeschäft von Hamburg aus initiiert ${ }^{213}$. Letzte Gewißheit kann es nicht geben, denn über Hackländers Aktivitäten im Jahr 1924 gibt es nur sehr wenig Archivmaterial. Sowohl spanische als auch französische Berichte gingen davon aus, daß Hackländer in Gardiners Waffenschmuggel verwickelt war ${ }^{214}$. Auch nach Erkenntnissen des britischen New Scotland Yard stand dies außer Frage ${ }^{215}$. Anhand der Quellenlage kann Hackländers Verwicklung allerdings nicht konkretisiert werden ${ }^{216}$.

Die Waffen wurden unter den Beni Ouriaghel, Beqqioua und Geznaya verteilt $^{217}$. Im Januar 1925 zählte der amerikanische Journalist Vincent Sheean allein in Ajdir 1200 brandneue Lebel-Gewehre ${ }^{218}$. Der Ethnologe David Hart

${ }^{212}$ CADN Maroc DAI 194: Bericht »Note au sujet du ravitaillement en armes et munitions du Rif par mer«, 30.5.1925; ADMAE Maroc 219, 130: Chef de bataillon de $2^{e}$ groupe d'aviation d'Afrique an Géneral de la division d'Oran, 5.7.1924; AN 313 AP 247: Tabor de police $\mathrm{N}^{\circ}$ 1, Note, 7.5.1925; CADN Tanger C39: Tabor de police $\mathrm{N}^{\circ} 1$, Bulletin de renseignements, 10.11.1925; SHAT 3H1557: Contrôle civil de Taourirt, Bulletin de renseignements, 17.10.1924; ABDELKRIM, Memoiren, S. 100; GABRIELLI, Abd-el-Krim, S. 14, S. 52.

${ }^{213}$ ADMAE Maroc 199, 122: Caïd Haddou an MAE, 29.9.1924 mit dem beiliegenden Bericht »Note confidentielle pour M. le Colonel Huot«; AN 475 AP 193: Bericht »La situation au Maroc en 1925-1926, La guerre du Rif, le passé, le présent, l'avenir«, 18.2.1926; FoNTANE, L'étrange aventure, S. 86.

${ }^{214}$ ADMAE Maroc 133, 136: Embajada de Paris an MAE, 30.12.1925 mit dem beiliegenden Annex II: »Note complémentaire sur Acklander«; AN F7, 14980: Bericht »Notice sur Gardiner« o.D. [1927]; ADMAE Maroc 133, 15: Notice o.D. [August 1925]; AN F7, 13413: MI, Sâreté générale, Bericht "Mission à Paris en septembre 1923 du frère d'Abd el Krim«, 20.7.1925; ADMAE Maroc 133, 93: Bericht "Trafic d'armes pour le Maroc«, 18.12.1925; APP BA 1678: MI, Süreté générale, Circulaire $\mathrm{N}^{\circ}$ 226, 26.9.1925; ADMAE Maroc 133, 145: Compte rendu, 7.10.1925; ADMAE Maroc 133, 148: Haut-Commissaire des provinces du Rhin, Bericht "Note au sujet des tentatives de vente de matériel et armes de guerre«, 26.11.1925; ADMAE Maroc 133, 130: Haut-Commissaire des provinces du Rhin an MAE, 30.12.1925; ADMAE Maroc 133, 134: Consulat de Mayence an MAE, 30.12.1925.

${ }^{215}$ PRO-FO 371, 11079, 39, 70: New Scotland Yard an FO, 10.8.1925.

${ }^{216}$ Im Politischen Archiv des Auswärtigen Amtes gibt es keine weitergehenden Informationen über Karl Hackländer. Auch das Wermelskirchener Stadtarchiv verfügt nur über wenige persönliche Daten. Der Verbleib des Nachlasses ist unbekannt [Mitteilungen des Stadtarchivs Wermelskirchen, 7.10.1998, 29.10.1998 und 19.11.1998; Mitteilung des Bergischen Geschichtsvereins, Abt. Wermelskirchen, 22.10.1998].

${ }^{217}$ SHAT 3H1103: Contrôle civil de Taourirt, Bulletin de renseignements, 14.9.1924; GABRIELLI, Abd-el-Krim, S. 14.

${ }^{218}$ SHEEAN, Riffis Fight, 12.2.1925. 
zitiert in seiner Studie über die Beni Ouriaghel ein Riflied aus dem Jahr 1925, in dem ein mit einem deutschen Gewehr kämpfender Abdelkrim besungen wird $^{219}$.

Die »Sylvia kehrte ein letztes Mal nach Gibraltar zurück und verrottete dort im Hafen ${ }^{220}$. Derweil hatte Gardiner mit seinen Begleitern Paris erreicht. Um möglichst wenig Aufsehen zu erregen, wurde Sibbera, so gut es ging, in einen Europäer verwandelt. Gardiner machte sich mit ihm nach Belgien und Holland auf. In Amsterdam und dann in Lüttich - dort mit dem Vermittler Gillon und mit einem südamerikanischen General - besprachen Gardiner und Sibbera die anstehenden Waffenkäufe ${ }^{221}$. Über seine Partner Mrs. M.C. Barton und John Preston sowie über die South Coast Trading Company hatte Gardiner mittlerweile in Scarborough den Fischdampfer $"$ Star of the Orient« kaufen lassen. Er lief am 16. Juli 1924 im Hafen von Antwerpen ein ${ }^{222}$. Gardiner ließ 36 Kisten mit Gewehren verladen, die mit Lastwagen aus Lüttich gekommen waren und nun als reine Salzladung deklariert wurden ${ }^{223}$. An Bord der "Star of the Orient« befanden sich neben Gardiner und Sibbera auch Mrs. Barton und deren Liebhaber Mathews, der einige Monate später versuchen sollte, Flugzeuge ins Rif zu schmuggeln. Harry Rawlings und Thomas Wate verließen das Schiff aus Furcht vor rechtlichen Folgen in Cherbourgh ${ }^{224}$.

Dort erfuhr Gardiner, daß die spanische Marine im Mittelmeer auf ihn wartete. Er beschloß, die französische Fahne zu hissen und so dicht wie möglich an der marokkanischen Küste entlang zu fahren, ohne Gibraltar anzulaufen. Gardiner zufolge schlüptte die »Star of the Orient» zwischen zwei spanischen Patrouillenbooten hindurch und erreichte mit Sibberas Hilfe Mitte August 1924 Marsa Beqqioua an der Rifküste ${ }^{225}$. 400 Lebel-Gewehre, 30 Tonnen Schwefel und 300 Doppelzentner Salz hatte Gardiner mit sich geführt. Er verlangte 80000 Peseten für die Lieferung. Si Mohammed Mohammedine Hitmi

${ }^{219}$ HART, The Aith Waryaghar, S. 400.

${ }^{220}$ PRO-FO 371, 11080, 94, 33: CO an FO, 20.4.1925.

${ }^{221}$ AN F7, 13413: Bericht "Déclaration de M. Deboe«, 30.7.1925; ADMAE Maroc 111, 1: Bericht »Renseignements donnés par El Hadj Hitmi«, 22.6.1926; BOUTBOUQALT, La Guerre du Rif, S. 35; KHARCHICH, La France, S. 162 u. S. 162, Anm. 1; SuEIRo SEOANE, España, S. 29; DiES., Contrabando, S. 265, Anm. 8.

${ }_{222}$ PRO-FO 371, 10583, 783, 27, 49, 52, 55: Embajada de Londres an FO, 4.7.1924, 18.7.1924, 23.7.1924 und 25.7.1924.

${ }^{223}$ PRO-FO 371, 10583, 783, 66: Embajada de Londres an FO, 9.8.1924; ADMAE Maroc 219, 17: Embajada de Paris an MAE, 31.12.1924; ADMAE Maroc 219, 154: Commissaire spécial de Marseille an Süreté générale de Paris, 17.10.1924; PRO-FO 371, 10583, 783, 70 : Embajada de Londres an FO, 12.8.1924; GABRIELLI, Abd-el-Krim, S. 14.

${ }^{224}$ PRO-FO 371, 10583, 783, 70: Embajada de Londres an FO, 12.8.1924; PRO-HO 45, 12067, 476042, 15: Embajada de Londres an FO, 31.12.1924.

${ }^{225}$ SHAT 3H1103: Contrôle civil de Taourirt, Bulletin de renseignements, 19.8.1924; PROFO 371, 12687, 11, 180: Minute, 22.2.1927; GARDINER, My Escape, 2.8.1925; Man of Many Adventures, in: Daily Mail, 21.5.1925. 
bewertete diese Forderung als übertrieben und bezahlte lediglich 42000 Peseten für die Fracht und 15000 Peseten für Gardiners Vermittlung. Die volle Summe sollte nur gegen die Vorlage von Quittungsbelegen entrichtet werden. Nachdem er mit seiner Ehefrau Ina nach Marseille zurückgekehrt war, beschwerte sich Gardiner, von Hitmi hereingelegt worden zu sein ${ }^{226}$. Seine Zeit als Waffenhändler für die Rifkabylen war nach seiner zweiten Fahrt ins Rif vorbei. Ende Dezember 1924 verkaufte er die »Star of Orient« in Marseille für 2600 Pfund $^{227}$.

Anfang November 1924 ging Abdelkrim einer seiner wichtigsten Mitstreiter verloren. Angeblich wegen einer Frauenaffäre wurde Sibbera von Rubio el Beqqioua - einem Schwager Caïd Haddous - ermordet. Der Täter wurde gleich im AnschluB am 3. November 1924 exekutiert. Abdelkrim vermutete spanische Machenschaften hinter der Tat ${ }^{228}$. Sibberas Nachfolger wurde Haddou ben Ali el Muqaddam ${ }^{229}$. Von 1925 an leitete nun Caïd Haddou ben Hammou die Nachschub- und Waffenlieferungen ${ }^{230}$.

Die vielen tausend Gewehre, die 1924 vor allem mit Charles Gardiners Mitwirkung ins Rif gelangten, benötigte Abdelkrim gerade in diesem Jahr in besonderem Maße. Zum einen startete er im Sommer seine große Offensive nach Westen, die mit der Besetzung Chichaouens und dem spanischen Rückzug zur Primo-de-Rivera-Linie endete. Zum anderen wollte Abdelkrim angesichts der ersten Scharmützel mit französischen Truppen an der Ouergha-Linie für die Zukunft gewappnet sein. Als General Primo de Rivera Anfang November 1924 seinen Unterhändler Horacio Echevarrieta ins Rif schickte, um erneut spanische Gefangene freizukaufen, forderte Si M'hammed neben 20 Millionen Peseten Lösegeld die Lieferung von zwölf Flugzeugen, 25 Artilleriegeschützen sowie 10000 Mauser-Gewehren mit Munition. Der Bruder Abdelkrims wollte, so sagte er, darauf vorbereitet sein, wenn Frankreich Spaniens

${ }^{226}$ ADMAE Maroc 111, 1: Bericht »Renseignements donnés par El Hadj Hitmi«, 22.6.1926; SHAT 3H442: Note de renseignements o.D. (Mitte 1926) mit Bezug auf Aussagen des deutschen Deserteurs Karl Ohme; BouTBOuQALT, La Guerte du Rif, S. 35; KHARCHICH, La France, S. 108, S. 162 u. S. 162, Anm. 1. Die 400 Gewehre waren - wie wir gesehen haben keinesfalls die einzige quantifizierbare Waffenlieferung Gardiners, wie die spanische Historikerin Susana Sueiro Seoane behauptet [SUEIRO SEOANE, Contrabando, S. 265, Anm. 8; DIES., España, S. 29].

${ }^{227}$ AN F7, 14679: MI, Commissariat spécial près de la préfecture an M. le Contrôleur général des services de recherches judiciares, 31.12.1924; CADN Maroc DAI 194: Bericht »Note au sujet du ravitaillement en armes et munitions du Rif par mer«, 30.5.1925.

${ }^{228}$ SHAT 3H1557: Contrôle civil de Taourirt, Bulletin de renseignements, 3.11.1924, 4.11.1924, 7.11.1924 und 21.11.1924; GODED LLOPIS, Marruecos, S. 91; SPENCER PRYSE, Through the Lines, S. 454-456; GABRIELLI, Abd-el-Krim, S. 6.

${ }^{229}$ PENNELL, A Country, S. 131; HART, The Aith Waryaghar, S. 378.

${ }^{230}$ CADN Madrid C263: MAE an Ambassade de Madrid, 4.9.1925 mit Bezug auf Aussagen des italienischen Deserteurs Antonio Palmeri; ADMAE Maroc 99, 244: EMA, $2^{e}$ bureau, Bericht »Renseignements sur Abd el Krim et sur la contrebande d'armes au Maroc«, 2.9.1925. 
Platz im Norden Marokkos einnehmen wolle ${ }^{231}$. Im Zuge der Niederlage seines Widersachers Ahmed el Risouni im Jebala-Gebiet erhielt Abdelkrim im Januar 1925 weiteren Nachschub an Geld und Waffen ${ }^{232}$.

Der französische Kontrollbeamte von Taourirt, Léon Gabrielli, schätzte, daß die Riftruppen Anfang 1925 über 20000 Lebel-Gewehre und 80000 spanische Mauser-Gewehre verfügten. Waffen- und Munitionsdepots befanden sich bei Ajdir sowie bei Targuist und Chichaouen ${ }^{233}$.

\subsection{Die Blockademaßnahmen Frankreichs und Spaniens}

Nachdem Frankreich seit April 1925 selbst in den Rifkrieg verwickelt war, wurde schnell Deutschland verdächtigt, Schmuggel mit dem Rif zu betreiben. Der Gedanke einer deutschen Konspiration entwickelte sich zu einer wahren Obsession, ohne daß es handfeste Beweise gegeben hätte ${ }^{234}$. Berichte über die Entsendung deutscher Offiziere ins Rif heizten die Stimmung auf ${ }^{235}$. Die "Kölnische Zeitung" beschuldigte die französische Regierung einer Pressekampagne, in der Deutschland »versteckt einer Beteiligung an den Vorgängen in Marokko beschuldigt « ${ }^{236}$ würde. Die französischen Behörden und Zeitungen nannten immer wieder die Namen Mannesmann ${ }^{237}$ und Adolf P. Langenheim aus Tetuan ${ }^{238}$. Der Grund für die Vorwürfe war, daß Reinhard Mannesmann und Langenheim während des Ersten Weltkrieges die deutsche "Marokko-Aktion« über Malaga mit Waffen beliefert hatten ${ }^{239}$.

${ }^{231}$ CADN Madrid C263: RG Rabat an MAE, 6.12.1924; SHAT 3H134: Ambassade de Madrid, Attaché militaire an MG, EMA, $2^{\mathrm{e}}$ bureau, 27.11.1924.

${ }^{232}$ PA-AA Madrid 135: Botschaft London an AA, 31.1.1925; WoOLMAN, Rebels in the Rif, S. 153.

${ }^{233}$ Gabrielli, Abd-el-Krim, S. 52; Fleming, Primo de Rivera and Abd-el-Krim, S. 226; BonNeT-DeVIlliers, La Guerte du Rif, S. 66; PARENT, Au Riff, S. 325.

${ }^{234}$ THIERRY, L'aggression, S. 409; SUEIRO SEOANE, Contrabando, S. 262.

${ }^{235}$ PA-AA Paris 454a: Botschaft Paris an AA, 26.5.1925.

${ }^{236}$ Die Kämpfe in Marokko, in: Kölnische Zeitung, 12.6.1925.

${ }^{237}$ AN F7, 13413: MI, Sûreté générale an EMA, $2^{e}$ bureau, 23.5.1925; ADMAE Maroc 220, 219: Gouverneur général de l'Algérie an MAE, 22.7.1925.

${ }^{238}$ ADMAE Maroc 220, 160: MAE an Ambassade de Madrid, 6.7.1925; CADN Maroc DAI 188: Tabor de police $\mathrm{N}^{\circ} 1$, Note, 10.5.1925; PA-AA Paris 454a: Botschaft Paris an AA, 4.6.1925 mit französischen Zeitungsberichten; L'agression des Rifains contre le Maroc francais, in: BCAF 35 (1925) S. 307; TERRIER, Les »Frères de la côte« 1925, S. 549; Des officiers allemands auprès d'Abd-el-Krim, in: Homme libre, 1.6.1925; Nos ennemis au Maroc, in: Journal, 1.6.1925; Bernard VERNIER, La politique islamique de l'Allemagne, Paris 1939, S. 83f.; FONTAINE, Abd el-Krim, S. 165.

${ }^{239}$ CADN Madrid C258: MAE an Ambassade de Madrid, 6.9.1919; SANCHEZ PEREZ, Abdelkrim, S. 153. 
Seit 1924 kursierten auch Berichte, daß deutsche U-Boote an der Rifküste gelandet seien, um Abdelkrim mit Nachschub zu versorgen ${ }^{240}$. Das Auswärtige Amt dementierte diese Meldungen jedoch ${ }^{241}$. Ein irischer Geschäftemacher namens J.P.D. Ryan aus Dublin gab vor, die deutschen Hintermänner des U-Boot-Handels zu kennen und ausschalten zu können. Er schaffte es sogar, im französischen Außenministerium vorgelassen zu werden. Dort verzettelte er sich allerdings in auffälliger Weise - vor allem, als er behauptete, die U-Boote hätten für ihre Beladung einen Flußhafen in der Schweiz angelaufen $^{242}$. Den Franzosen fiel nun auf, daß viele seiner Informationen öffentlich bekannt waren, und schickten ihn zurück nach Irland ${ }^{243}$.

Der marokkanische Historiker Tayeb Boutbouqalt erklärt die französische Pressekampagne gegen Deutschland damit, daß der französischen Öffentlichkeit weisgemacht werden sollte, die Feinde Frankreichs im Rif seien die gleichen wie während des Ersten Weltkrieges gewesen. Der Eindruck sollte erweckt werden, daß die Rifkabylen ihren Kampf ohne diese Hilfe nicht hätten durchführen können ${ }^{244}$. Der französische Nachrichtendienst Deuxième bureau ging noch weiter und entwickelte erfundene Szenarien einer islamistischkommunistischen Weltverschwörung gegen Frankreich und seine Kolonien, die zum Teil aus Deutschland koordiniert worden sein soll ${ }^{245}$.

Jedes deutsche Schiff war für die Militärs verdächtig. Schiffahrtslinien wie die Neptun oder die Oldenburgisch-Portugiesische Dampfschiffahrtsgesellschaft (OPDG) wurden in der Folgezeit observiert ${ }^{246}$. Die Jagd auf vermeintliche deutsche Schmuggler führte im Juni 1925 fast zu einer diplomatischen Krise zwischen Frankreich und Deutschland. Anfang des Monats brachte der

${ }^{240}$ AN F7, 13413: Bericht "Le mouvement riffain et l'aide intermusulmane«, 10.9.1925; SHAT 3H1557: Région de Fes, SR, Bulletin de renseignements, 9.5.1924; SHAT 3H1558: Commandant du cercle de Guercif an Commandant de la territoire de Taza, 6.5.1925; CADN Maroc DAI 194: Bericht »Note au sujet du ravitaillement en armes et munitions du Rif par mer«, 30.5.1925; ADMAE Maroc 100, 105: RG Rabat an MAE, 13.11.1925; CADN Tanger C40: Tabor de police $\mathrm{N}^{\circ}$ 1, Renseignements, 29.3.1926; Lettre apocryphe, in: Figaro, 13.5.1925; Foreigners Aid Abd el Krim, in: New York Times, 13.5.1925; L'agression des Rifains contre le Maroc français, in: BCAF 35 (1925) S. 259; Die Lage in Marokko, in: Kōlnische Zeitung, 13.5.1925.

${ }^{241}$ PA-AA Paris 454a: Botschaft Paris an AA, 16.5.1925.

${ }^{242}$ ADMAE Maroc 219, 212: Consulat de Dublin an MAE, 14.5.1925; CADN Londres C519: J.P.D. Ryan an Embassy of France, London, 19.5.1925 und 20.5.1925; ADMAE Maroc 219, 215, 217: Consulat de Dublin an MAE, 20.5.1925 und 22.5.1925; ADMAE Maroc 219, 219: MAE an Consulat de Dublin, 23.5.1925; ADMAE Maroc 219, 235: Bericht »Contrebande d'armes destinées au Riff«, 17.6.1925.

${ }^{243}$ ADMAE Maroc 219, 239: MAE an Consulat de Dublin, 22.6.1925.

${ }^{24}$ BOUTBOUQALT, La Guerre du Rif, S. 56.

${ }^{245}$ RIVET, Le commandement français, S. 107; OVED, La contribution, S. 71-74, S. $79 f$.

${ }^{246}$ CAOM Algérie 1CM1: Ministère de la Marine, Etat-major, $2^{e}$ bureau, Note de renseignements, 3.7.1925; ADMAE Maroc 99, 135: EMA, $2^{e}$ bureau, Bericht »Bâtiments suspects de contrebande pour le Maroc«, 4.8.1925; MONTORO OBRERO, Tráfico de armas, S. 257. 
französische Kreuzer "Metz» die deutschen Fischdampfer »Leipzig» und "Dortmund « in den Gewässern vor Agadir auf - also an der marokkanischen Atlantikküste. Die deutschen Schiffe hatten die Sperrlinie von sechs Meilen nicht beachtet und sich etwas zu nah an der Küste aufgehalten ${ }^{247}$. Der Eigner, die Bremer Dampfschiffahrtsgesellschaft, beschwerte sich vehement beim Auswärtigen Amt, zumal die Boote schon monatelang unbehelligt vor der marokkanischen Küste gefischt hatten ${ }^{248}$. Als noch ein dritter Fischkutter - die "Halle« - förmlich geentert wurde, vermerkte Ministerialdirektor Köpke, daß die Zwischenfälle »Öffentlichkeit und auch Parlament zu beunruhigen ${ }^{249}$ begännen. Da die Durchsuchung in Mogador nur Fische, aber keine Waffen zu Tage förderte, konnten die Kapitäne der Schiffe lediglich wegen verbotenen Fischfangs belangt werden ${ }^{250}$.

Die deutschen Diplomaten versuchten, Deutschland aus allen Schlagzeilen herauszuhalten, die im Zusammenhang mit Marokko standen. Als die Hamburger Waffenexportfirma Carl W. Heins ihrer Werbeanzeige in der spanischen Zeitung "El comercior vom 12. Mai 1925 das Abbild eines kriegerisch dreinblickenden Marokkaners beifügte, der in seinem Aussehen an Abdelkrim erinnerte, wies das Auswärtige Amt den Inhaber "nachdrücklichst auf die durch eine derartige Geschäftspropaganda hervorgerufene Schädigung deutscher Interessen« hin, woraufhin dieser die Reklame zurückzog ${ }^{251}$. Deutsche Stellen gingen Verdächtigungen nach. Als etwa die Zeitung "Ėre nouvelle« meldete, daß Mitglieder des Roten Halbmondes in München mit einem Ahmed Ihsan Bey an der Spitze Waffen, Munition und Medikamente über Hamburg nach Marokko liefern würden, leitete das bayerische Staatsministerium des Äußeren - allerdings ergebnislose - Ermittlungen ein. Ahmed Ihsan Bey stellte sich als harmloser Oberstudieninspektor für in Deutschland lebende türkische Studenten heraus ${ }^{252}$.

Die längst nicht immer zutreffenden Vorwürfe der französischen Geheimdienste richteten sich auch gegen Großbritannien ${ }^{253}$. Ihr Verdacht, Abdelkrims Truppen würden britische Patronen der Marke Western 2-17 benutzen, klärte

\footnotetext{
${ }^{247}$ ADMAE Maroc 98, 58: MAE an Ambassade de Berlin, 10.6.1926; PA-AA Paris 454a: Botschaft Paris an AA, 9.6.1925.

${ }^{248}$ PA-AA Paris 454a: AA an Botschaft Paris, 10.6.1925.

${ }^{249}$ PA-AA Paris 454a: AA an Botschaft Paris, 17.6.1925.

${ }^{250}$ Die Kämpfe in Marokko, in: Kölnische Zeitung, 10.6.1925; Die deutschen Fischerboote an der marokkanischen Küste, in: Kölnische Zeitung, 20.6.1925.

${ }^{251}$ PA-AA R72044, L057933: Generalkonsulat Barcelona an AA, 5.6.1925; PA-AA Paris 454a: AA an Botschaft Paris, 30.7.1925.

${ }^{252}$ Le Croissant Rouge, in: Ėre Nouvelle, 29.6.1925; PA-AA Paris 454a: Bayerisches Staatsministerium des Äußeren an AA, 28.8.1925.

${ }^{253}$ OVED, La contribution, S. 74.
} 
sich anders auf als erwartet. Französische Behörden selbst hatten 1924 Munition dieser Marke an einheimische Bewacher von Farmen britischer Staatsangehöriger ausgehändigt. Auf diesem Weg waren sie ins Rif gelangt ${ }^{254}$.

Auch aus italienischen, griechischen, russischen, tschechoslowakischen, irischen oder holländischen Quellen soll Abdelkrim mit militärischem Nachschub beliefert worden $\operatorname{sein}^{255}$. Vor allem die Niederlande wurden häufig genannt. Schon im Juli 1923 war ein holländischer Dampfer zwischen Alhucemas und dem Peñon de Vélez de la Gomera von der spanischen Marine aufgebracht worden. Im Hafen von Ceuta fanden die Spanier dann im Schiffsrumpf Maschinengewehre und Munition ${ }^{256}$. Berichte französischer Stellen blieben aber zumeist sehr vage und lieferten selten Details, wie etwa im Fall des in Holland lebenden Engländers Claude Capron. Er lieferte mit den Holländern F.J.W. Soer und J.C. Lensvelt aus Rotterdam auf Schiffen der Bugsier Lijn Lebensmittel nach Algier, die von dort weiter ins Rif transportiert wurden ${ }^{257}$. Zusammen mit dem Holländer Jan den Engelsen war Capron in ein Geschäft mit 10000 für das Rif bestimmten Parabellum-Pistolen verwickelt ${ }^{258}$. Ein Mann namens Flesch organisierte in Amsterdam den Waffenschmuggel für das Rif $^{259}$. Berichten französischer Sicherheitsdienste zufolge

${ }^{254}$ PRO-FO 371, 11081, 186, 158: CG Rabat an FO, 23.12.1925 mit Bezug auf den beiliegenden Brief Vice-Consul of Fez an CG Rabat, 21.12.1925; Munitions for the Riff, in: Al-Moghreb al Aksa \& Tangier Gazette, 9.1.1926.

${ }^{255}$ Italien: CADN Tanger C38: RG Rabat an CG Tanger, 4.2.1928, CADN Maroc DAI 194: Bericht »Note au sujet du ravitaillement en armes et munitions du Rif par mer«, 30.5.1925; SHAT 3H102: Renseignement, 7.7.1925; AN F7, 13413: MI, Sûreté générale an Préfet des Bouches-du-Rhône, 5.9.1925; CADN Rome A453: Consulat de Turin an Ambassade de Rome, 17.7.1925; Griechenland: AN F7, 13413: MAE an MI, Sûreté générale, 13.7.1925; ADMAE Maroc 99, 92: MAE an RG Rabat, 13.7.1925; Rußland: ADMAE Maroc 220, 47: Ambassade de Madrid an MAE, 5.6.1925; AN F7, 13413: Bericht "Le mouvement riffain et l'aide intermusulmane«, 10.9.1925; AN F7, 13413: MI, Sûreté générale an MAE, 25.11.1925; SHAT 3H102: EMA, $2^{c}$ bureau, Renseignement, 20.8.1925; PA-AA R31764, K599912: Konsulat Odessa an Botschaft Moskau, 13.5.1925; Tschechoslowakei: SHAT 3H102: EMA, $2^{\mathrm{e}}$ bureau, Renseignement, 7.7.1925; Irland: ADMAE Maroc 219, 227: Consulat de Dublin an MAE, 4.6.1925; Niederlande: ADMAE Maroc 220, 145: MG, EMA an MAE, 2.7.1925; CADN Tanger C39: Tabor de police $\mathrm{N}^{\circ} 1$, Information, 19.7.1925; PA-AA Paris 454a: Botschaft London an AA, 2.7.1925; ADMAE Maroc 99, 113: EMA, $2^{e}$ bureau, SR, Renseignement, 27.7.1925; SHAT 3H102: EMA, $2^{e}$ bureau, Bericht $» C o n t r e-$ bande d'armes pour le Maroc«, 29.9.1925.

${ }^{256}$ Mystery Machine-Guns for the Riff, in: Times, 23.7.1923.

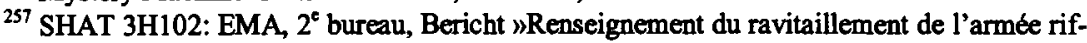
faine«, 15.10.1926; SHAT 3H102: EMA, $2^{c}$ bureau, Renseignement, 28.10.1925.

${ }^{258}$ SHAT 3H102: EMA, $2^{c}$ bureau, Renseignement, 17.1.1926; CADN Londres C520: MAE an Ambassade de Londres, 30.3.1926.

${ }^{259}$ ADMAE Maroc 133, 145: Compte rendu, 7.10.1925. 
wurden auch Waffen heimischer Fabrikation von Calais und Dünkirchen aus über den Umschlagplatz Antwerpen sowie von den Mittelmeerhäfen Marseille und Sète zu den Rifkabylen transportiert ${ }^{260}$.

Am 24. Juni 1925 einigten sich Frankreich und Spanien auf eine gemeinsame Seeblockade ${ }^{261}$. Diesem ersten Vertrag folgten am 8. Juli 1925 ein weiterer Kontrakt über die Eindämmung des Waffenschmuggels zu Lande sowie am 21. Juli 1925 die Einigung über die Bewachung der internationalen Zone von Tanger. Das direkte Manövrieren von Schmuggelschiffen an der Küste entlang konnten die schweren Kriegsschiffe jedoch nicht verhindern. Kleine Barken konnten durch das Netz schlüpfen ${ }^{262}$.

Die Rifkabylen versuchten, die Blockade zu überlisten. Ihnen gelang es über Helfer aus Gibraltar, die Funkbefehle für den Einsatzort der spanischen und französischen Schiffe abzufangen ${ }^{263}$. Da die Motivation der alliierten Marinesoldaten eher gering war, kam es nur selten zu Kaperungen oder Beschüssen von Schmuggelschiffen ${ }^{264}$. Tanger-Korrespondent Walter Harris wunderte sich in einem Brief an die »Times«, daß die spanischen Schiffe im Hafen von Tanger vor Anker lägen, anstatt sich zusammen mit Frankreich an der Blockade der Rifküste zu beteiligen. Thre Kapitäne würden ihre Kohleladung unter anderem an den englischen Besitzer des Cecil-Hotels verkaufen ${ }^{265}$.

Mit der Errichtung der Oficina mixta, eines in Malaga stationierten spanisch-französischen Koordinationsbüros für die verschiedenen Nachrichtendienste, intensivierten die Verbündeten ihre Bemühungen, die Nachschublieferungen $\mathrm{zu}$ unterbinden ${ }^{266}$. Die Zeiten für Schmuggler wurden härter. Ende 1925 zeigte die Blockade auch an Land um die internationale Zone von Tanger Wirkung. Nachschub und Munition wurden im Rif immer knapper ${ }^{267}$.

${ }^{260}$ AN F7, 13413: MAE an MI, Süreté générale, 15.6.1925; CAOM Algérie 1CM1: Direction générale des douanes, Service générale an Ministère de la Marine, 19.6.1925; SHAT 3H102: EMA, $2^{e}$ bureau, Bericht »Trafic d'armes via Anvers«, 15.10.1925.

${ }^{261}$ MONTORO OBRERO, Tráfico de armas, S. 259; KHARCHICH, La France, S. 306-322; HUETZ DE LEMPS, La collaboration, S. 94f.; ESPAÑA, La actuación, S. 70-73.

${ }_{262}$ PRO-AIR 5, 722: Bericht »A Study of the Air Aspect of the France-Riff War 1925-1926« von Lt. D.L. Blackford (1930), S. 10; CAOM 10 APOM 295: Bericht von Robert Montagne "L'affaire riffaine - Abd el Krim«, 28.5.1937; Walter B. HARRIS, Gun-Running on Rif Coast, in: Times, 3.9.1925.

${ }^{263}$ LOZE, Tanger, 6.4.1926.

${ }^{264}$ CADN Maroc DAI 194: Bericht »Note au sujet du ravitaillement en armes et munitions du Rif par mer«, 30.5.1925.

${ }^{265}$ TNLA, BNS, 1, Williams: Walter Harris an Harold Williams, 13.10.1925.

${ }^{266}$ HUETZ DE LEMPS, La collaboration, S. 101; SHAT 3H102: MG, EMA, $2^{\mathrm{c}}$ bureau, Bericht "Note pour la section d'études", 19.12.1925; PA-AA R72045: AA an Botschaft Madrid, 28.11.1925.

${ }^{267}$ Fleming, Primo de Rivera and Abd-el-Krim, S. 324; SHEEAN, Die Armee Abd el Krims, 8.11.1925; SHAT 3H102: RG Rabat an MG, EMA, $2^{e}$ bureau, 13.2.1926 mit Bezug auf Aussagen von Mario Magri. 
Abdelkrim, der noch im Juni 1925 gegenüber dem italienischen Journalisten Mirko Ardemagni angekündigt hatte, das Rif könne selbst bei einer vollständigen Blockade drei Jahre ausharren ${ }^{268}$, versuchte nun, Munition auf umliegenden Märkten aufzukaufen. Frauen versteckten sie häufig unter ihrer Kleidung ${ }^{269}$. Ein deutscher Deserteur und ein Rifkabyle wurden damit beauftragt, benutzte Patronenhülsen wieder aufzufüllen ${ }^{270}$. In einer Art Munitionsfabrik bei Ajdir stellten 60 Arbeiter aus dem Rif neue Patronen her. Dem schwedischen Journalisten Hans Langlet zufolge dienten einige Scheinkapitulationen von Kabylen der List, hinter den französischen oder spanischen Linien Waffen zu kaufen und sie ins Rif zu überführen ${ }^{271}$.

Der Nachschub an Lebensmitteln kam infolge der Blockade praktisch zum Stillstand. Die Bestände an Weizen gingen Ende 1925 aus. Dieser Effekt wurde durch die Bombardierungen der spanischen und französischen Flugzeuge, die gezielt Märkte und Felder innerhalb des Rifs zerstörten, noch verstärkt. Der dadurch entstandene Unmut wurde Abdelkrim 1926 zum Verhängnis, als zahlreiche Kabylen ihm die weitere Gefolgschaft verweigerten und sich dem Gegner unterwarfen ${ }^{272}$.

\subsection{Abdelkrims Pläne von einer Luftwaffe des Rifs}

Ein Aspekt des Schmuggelhandels mit dem Rif verdient besondere Beachtung, denn von Beginn des Rifkrieges an plante Abdelkrim die Gründung einer eigenen Luftwaffe, um seinem Volk zu zeigen, »daß ich wirklich über die modernsten Kampfmittel verfüge ${ }^{273}$. Den Spaniern war die Gefahr bewußt. Nach der Niederlage von Annual zerstörten die zurückweichenden Truppen auf dem Flughafen von Selouane acht Flugzeuge, damit sie nicht in die Hände der Rifkabylen fielen ${ }^{274}$. Und schon eher vage Informationen, daß Abdelkrim 1921 in Großbritannien Flugzeuge kaufen wolle, reichten aus, damit die spanische

\footnotetext{
${ }^{268}$ Mirko ARDEMAGNI, Abd el Krim asserisce a un nostro inviato che egli, volendo, sarebbe già a Fez, in: Popolo d'Italia, 16.6.1925.

${ }_{269}$ PENNELL, Women and Resistance, S. $113 \mathrm{f}$.

${ }^{270}$ CADN Tanger C38: Chef de la sûreté de Fès an Chef du bureau régional des renseignements de Fès, 14.12.1925; CADN Tanger C37: Tabor de police $\mathrm{N}^{\circ} 1$, Bericht $» R e n s e i g n e-$ ment de source espagnole«, 18.12.1925; CAOM Algérie 30H86: Commune mixte de Nuédroma an Gouverneur général de l'Algérie, 19.12.1925.

${ }^{271}$ LANGLET, Abdel Krim's Views, 29.4.1926; DERS., How the Riffis Fight, 4.5.1926.

${ }^{272}$ FLEMING, Primo de Rivera and Abd-el-Krim, S. 324f.

${ }^{273}$ ABDELKRIM, Memoiren, S. 103.

${ }^{274}$ PRO-FO 371, 7067, 184, 72: Consul of Tetuan an FO, 28.7.1921.
} 
Botschaft in London sie an das britische Außenministerium weiterreichte ${ }^{275}$. Eine dort eingeleitete Untersuchung ergab indes keine Bestätigung für die spanischen Behauptungen ${ }^{276}$.

Pläne, innerhalb des Rifs eine eigene Luftwaffe aufzubauen, existierten seit Ende $1921^{277}$. Daniel Bourmancé-Say, Abdelkrims Vertrauter im algerischen Port-Say, bemühte sich um Kontakte nach Frankreich, um dort zwei Flugzeuge zu erwerben. Sie sollten in Kisten verpackt nach Port-Say geschickt werden. Bourmancé-Say schlug vor, für die spanischen Gefangenen ein Lösegeld zu verlangen, um es dann für den Flugzeugkauf zu verwenden ${ }^{278}$. Als er im Februar 1922 mit einer Rifdelegation nach Paris aufbrach, diente diese Reise auch dem Zweck, über den Journalisten Jean du Taillis Flugzeuge anzuschaffen $^{279}$. In der Erwartung zweier Maschinen richteten die Rifkabylen bei Oued Nokour ein Gelände für deren Landung her ${ }^{280}$. Doch das geplante Geschäft mit du Taillis, der zudem Piloten und Mechaniker anwerben sowie Ersatzteile organisieren sollte, platzte, obwohl der Franzose noch im August 1922 brieflich beteuerte, die Landung eines Flugzeugs im Rif sei durchführbar ${ }^{281}$.

Erst als Abdelkrim durch den Freikauf der spanischen Gefangenen im Januar 1923 mehr als vier Millionen Peseten einnahm, war wieder an den Erwerb von Flugzeugen zu denken. Fast hätten die Spanier ihm unfreiwillig geholfen. Zwei notgelandete Flugzeuge bei Cabo Quilates und in der Hochebene von Targuist waren jedoch zu stark beschädigt, als daß sie hätten repariert werden können ${ }^{282}$. Ein im Melillabezirk niedergegangenes spanisches Flugzeug war ebenso nicht mehr brauchbar wie drei bis vier im Gefecht abgeschossene Maschinen, obwohl spanische Gefangene zu ihrer Instandsetzung herangezogen wurden ${ }^{283}$.

Im April 1923 bestellte Si M'hammed während eines Aufenthaltes in Paris vom Engländer Charles Gardiner vier Jagd- sowie acht Bomber-Flugzeuge, Tausende von Bomben - darunter 50 Gasbomben -, zwei Ersatzmotoren, Er-

${ }^{275}$ PRO-FO 371, 7067, 184, 144: Embajada de Londres an FO, 19.8.1921.

${ }^{276}$ PRO-FO 371, 7068, 184, 122: Disposal and Liquidation Commission an FO, 1.10.1921; PRO-MUN 4, 6142: Aircraft Disposal Company an FO, 29.6.1922.

${ }^{277}$ KHARCHICH, La France, S. 111.

${ }^{278}$ CADN Maroc DAI 198: Daniel Bourmancé-Say an Abdelkrim, 5.12.1921.

${ }^{279}$ KHARCHICH, La France, S. 150, Anm. 4; TAHTAH, Pragmatisme 1995, S. 103.

${ }^{280}$ CADN Tanger A 427: Renseignements, 31.3.1922.

281 ADMAE Maroc 112, 221: Jean du Taillis an Abdelkrim, 14.4.1922; ADMAE Maroc 112, 250: Jean du Taillis an Si M'hammed o.D. [1922]; CADN Maroc DAI 197: Jean du Taillis an Si M'hammed, 8.8.1922; FonTAINE, L'etrange aventure, S. 100; DERS., Abd el-Krim, S. 90.

${ }^{282}$ GODED LLOPIS, Marruecos, S. 101f.; Lón ROLLIN, L'Espagne au Maroc et la question de Tanger, in: BCAF 34 (1924) S. 320-324, S. 322.

${ }^{283}$ PRO-FO 371, 8342, 171, 37: Consul of Tetuan an FO, 14.6.1922; CADN Maroc DAI 187: RG Rabat an MAE, 22.12.1923; GABRIELLI, Abd-el-Krim, S. 50; FRUNSE, Zivilisatoren, S. 523. 
satzteile und Flugbenzin. Angefordert wurden auch 15 Piloten und acht Mechaniker ${ }^{284}$. Gardiner konnte die Erwartungen nicht erfüllen. Den Engländer Louis de La Garde vom Londoner Royal Aero Club, der Abdelkrim im Sommer 1923 vier Flugzeuge verkaufen wollte, wimmelte der Rifchef ab, weil er keine Liefergarantien vorweisen konnte ${ }^{285}$. Als der in Oran lebende Handelsvertreter Alfred Garnier am 4. Oktober 1923 anbot, eine Gesellschaft für die Erschließung der Bergbaufelder im Rif zu gründen, forderte Caïd Haddou zunächst den Nachweis, daß er in der Lage sei, ein Jagdflugzeug zu beschaf$\mathrm{fen}^{286}$.

Abdelkrim wandte sich auch direkt an Flugzeugfirmen. Scherif Moulay Mohammed ben Moulay Mohammed Salah el Tidjani, ein Abenteurer aus Tunesien, hielt sich im Sommer 1923 in Frankreich auf und besaß einen Brief der Firma Bréguet mit einem Verkaufsangebot von vier Jagdflugzeugen zu je 40000 Francs ${ }^{287}$. Lose Kontakte bestanden über Don Matéo Donal aus Oujda zu den englischen Firmen Napier \& Son Ltd. und Havilland Aircraft Compa$n y^{288}$. Den Verbindungen der Rifkabylen in die USA schob das dortige State Department einen Riegel vor ${ }^{289}$.

Anfang 1924 lagen dem neuen Luftfahrtminister Caïd Haddou Angebote von mehreren französischen Flugzeugfirmen vor ${ }^{290}$. Die Algerienfranzosen Nicolas Mazella und Joseph Abad aus Oran - letzterer ein ehemaliger Pilot - hatten laut Vertrag mit der Rifregierung den Auftrag, Piloten, Mechaniker und Spezialisten für Flugzeugmotoren anzuwerben sowie Jagdflugzeuge aufzukaufen, die mit einem Dampfer ins Rif geschafft werden sollten ${ }^{291}$. Abad

284 ADMAE Maroc 111, 25: Vertrag zwischen der Rifregierung und Charles Gardiner, 30.4.1923; KHARCHICH, La France, S. 454f.

${ }^{285}$ CADN Madrid C274: MAE an Ambassade de Madrid, 27.8.1923 mit Bezug auf den marokkanischen Übersetzer, der La Garde begleitete.

${ }^{286}$ CAOM Algérie 30H86: Préfet du départment d'Oran an Gouverneur général de l'Algérie, 22.10.1923.

${ }^{287}$ ADMAE Maroc 196, 132: RG Rabat an MAE, 20.7.1923 mit einem Bericht des Commissaire divisionnaire aus Casablanca, 18.7.1923.

${ }^{288}$ SHAT 3H1559: Commissariat de la sûreté régionale Oujda an Consul général de France Oujda, 22.10.1923; ADMAE 219, 29: RG Rabat an MAE 9.1.1924; ADMAE Maroc 219, 62: EMA, $2^{\circ}$ bureau, Renseignements, 14.2.1924.

${ }^{289}$ Luella J. HALL, The United States and Morocco 1776-1956, Metuchen 1971, S. 757.

${ }^{290}$ SHAT 3H1558: Région de Taza, Poste d'Hassi Ouenzga, SR, Bericht »Feuille de renseignements sur le Riff (d'apres les impressions du voyage du Docteur Marion-Gallois)", 4.12.1923; ADMAE Maroc 219, 36: Consul général de France Oujda an RG Rabat, 11.1.1924; FONTAINE, L'étrange aventure, S. 72.

${ }^{291}$ ADMAE Maroc 220, 151: Vertrag zwischen der Rifregierung und Joseph Abad, Nicolas Mazella, 15.10.1923; SHAT 3H1559: Commissariat de la sûreté régionale Oujda, Renseignements, 30.12.1923. 
stand tatsächlich mit der Société anonyme d'études et de constructions aéronautiques für den Kauf von zehn 300 PS starken Monoplan in Verbindung, die über eine Million Francs kosten sollten. Das Geschäft wurde jedoch nie realisiert $^{292}$.

Der Kontakt zu einer Fluggesellschaft nach Algerien verhieß mehr Erfolg. 1923 hatte die Société du réseau aérien transafricain (S.R.A.T.) mit vier für den Passagierflug umgebauten Bréguet-Militärmaschinen den Linienflug auf der Strecke Algier-Biskra-Touggourt aufgenommen. Schnell wurde festgestellt, daß die Motorleistung der Flugzeuge für diese Entfernung unzureichend war. Daher sollten sie verkauft werden ${ }^{293}$.

Am 21. November 1923 stiegen im Hotel Transatlantique von Oujda zwei Männer ab. Es handelte sich um den früheren Militärflieger und nunmehrigen S.R.A.T.-Agenten von Algier, Capitaine Ducas, und um Georges-Marie Haardt, dem ein Jahr zuvor noch mit fünf Citroën-Raupenfahrzeugen die erste motorbetriebene Durchquerung der Sahara von Touggourt nach Timbuktu geglückt war $^{294}$. Die neukonzipierten Kettenfahrzeuge, die Haardt getestet hatte, sollten militärischen Zwecken dienen. Die Reise regte seine Faszination für Abenteuer an. Von 1924 bis 1925 sollte er auf einer $20000 \mathrm{~km}$ langen Fahrt Äquatorialafrika durchqueren, 1931 von Beirut nach Peking fahren ${ }^{295}$.

Gleichzeitig trafen sich im Café de la bourse von Oujda der Italiener Poduje - der S.R.A.T.-Agent von Biskra - und Eugène Allard aus Oran, der die Zeitung "Tablettes marocaines« herausgab. Allard fungierte als Mittelsmann der Rifkabylen. Die vier Männer vereinbarten, daß die vier zum Verkauf stehenden Maschinen - zur Vermeidung von Komplikationen für die S.R.A.T. - an

${ }^{292}$ ADMAE 220, 154: Société anonyme d'études et de constructions aéronautiques an Joseph Abad, 6.12.1923.

${ }^{293}$ ABDELKRIM, Memoiren, S. 102f.; ADMAE Maroc 219, 36: Consul général de France Oujda an RG Rabat, 11.1.1924 mit Bezug auf den Bericht »Tentations faites à Alger par les chefs riffains pour acheter des avions français« des Italieners Poduje. Dieser durch andere Quellen weitgehend bestätigte Bericht gilt für das Folgende - soweit nicht anders zitiert - als Grundlage. Der Flugzeugkauf der Rifkabylen in Algerien wird in der Forschungsliteratur nur beiläufig erwähnt [KHARCHICH, La France, S. 111; PAYNE, Politics, S. 493, Anm. 7; FLEMING, Primo de Rivera and Abd-el-Krim, S. 225; GODED LloPIS, Marruecos, S. 102; FURNEAUX, Abdel Krim, S. 91; SÁNCHEZ PÉREZ, Abdelkrim, S. 153; DAOUD, Abdelkrim, S. 160; am ausführlichsten noch FONTAINE, L'étrange aventure, S. 99-105].

${ }_{294}$ In den Quellen ist von einem »Cart« bzw. »Kart« oder »Kardt«, einem »Schweizer« aus Algier, die Rede. Da diese Person mit dem Chef der Citroën-Mission in die Sahara gleichgesetzt wird, kann es sich nur um Georges-Marie Haardt gehandelt haben, der sich damals auch in Algerien aufhielt [CADN Maroc DAI 192: RG Rabat an DAI Rabat, 5.1.1924; SHAT 2H1559: Commissariat de la sûreté régionale Oujda, Renseignements, 26.12.1923 und 28.12.1923]. Zur Saharafahrt: Georges-Marie HAARDT, Louis AUDOUIN-DUBREUIL, La première traversée du Sahara en automobile, Paris 1923.

${ }^{295}$ Jacques WOLGENSINGER, André Citroën, Stuttgart 1992, S. 65, S. 149f., S. 168f., S. 177; Sylvie SchweItZER, André Citroën. Pour une histoire du XXe siècle, Lyon 1992, S. 39f., S. 123, S. 161-179, S. 228. 
Georges-Marie Haardt veräußert werden sollten. Dieser hatte sie an Allard weiterzuleiten, der sie dann im Anschluß an das Rif übergeben sollte. Es galt den Eindruck zu vermeiden, daß eine französische Firma Abdelkrim direkt Flugzeuge verkaufte. Ducas und Haardt verließen Oujda, ohne einen Rifkabylen getroffen zu haben. Jedes Flugzeug kostete 100000 Francs, zahlbar nach Lieferung. Für jede gelieferte Maschine sollte Allard 20000 Francs Provision erhalten, nach der kompletten Beendigung der Transaktion noch einmal zusätzlich 140000 Francs $^{296}$. Abdelkrim gab seinen Gesandten Caïd Haddou und Si Mohammed Azerkane, als sie nach Algerien aufbrachen, den strikten Befehl mit, »die Zahlung erst zu leisten, bis die Apparate abgeflogen seien ${ }^{297}$.

Ein weiterer Geschäftspartner war Pierre Ghisolfi, Rechtsanwalt in Oujda und Sohn des Unterpräfekten von Tlemcen ${ }^{298}$. Am 21. Dezember 1923 begleitete er Eugène Allard, Azerkane und Haddou von Oujda nach Algier. Die Gruppe bewohnte gemeinsam ein Hotel. Azerkane bezahlte alle Rechnungen. Am Flughafen Hussein-Dey begutachteten die beiden Rifkabylen die Flugzeuge. S.R.A.T.-Agent Poduje hatte mittlerweile einen Piloten seiner Fluglinie aufgetrieben, der für kurze Zeit die Linie Algier-Biskra geflogen hatte. Es handelte sich um den 26jährigen Raymond Perrier aus Combreaux, der nun als Mechaniker in Algier arbeitete ${ }^{299}$. Am 23. Dezember 1923 unternahm Perrier zunächst zusammen mit Caïd Haddou einen Versuchsflug in der Region Algier $^{300}$.

Einen Tag später starteten die beiden um sieben Uhr morgens, um die erste Maschine ins Rif zu überführen. Als Perrier in Tlemcen zwischenlandete, mußte er, da kein Flugbenzin aufzutreiben war, mit 50 Litern Autobenzin vorliebnehmen. Am nächsten Morgen ging der Flug weiter. Zur Orientierung verwendete Perrier eine Straßenkarte. Trotz des Morgennebels gelang es ihm, am 25. Dezember 1923 gegen zehn Uhr bei Toufist in der Nähe von Ajdir zu landen. Für den Flug erhielt er 3500 Francs Prämie. Das Flugzeug wurde unter Bäumen und Geäst versteckt ${ }^{301}$.

Im Rif herrschte wegen der Landung großer Enthusiasmus. Die kühnen Pläne Abdelkrims schienen in greifbare Nähe gerückt: »Meine Feinde hätten sich beim Anblick eines Rifapparates über Larache, Tetuan und Melilla nicht we-

${ }^{296}$ ADMAE Maroc 219, 2: Gouverneur général de l'Algérie an MAE, 27.12.1923; ADMAE Maroc 219, 17: Gouverneur général de l'Algérie an MAE, 1.1.1924.

${ }^{297}$ ABDELKRIM, Memoiren, S. 103.

${ }^{298}$ CADN Maroc DAI 192: RG Rabat an DAI Rabat, 5.1.1924.

${ }^{299}$ SHAT 3H1559: Commissariat de la sûreté régionale Oujda, Renseignements, 30.12.1923; ADMAE Maroc 219, 65: RG Rabat an MAE, 18.2.1924.

${ }^{300}$ ADMAE Maroc 219, 17: Gouverneur général de l'Algérie an MAE, 1.1.1924; FONTAINE, L'étrange aventure, S. 74.

${ }^{301}$ ADMAE Maroc 219, 66: Consul général de France Oujda an RG Rabat, 29.1.1924; SHAT 3H442: Note de renseignements o.D. [Mitte 1926] nach Aussagen von Karl Ohme; GODED LLOPIS, Marruecos, S. 102; SHEEAN, My Meeting, S. 848. 
nig gewundert ${ }^{302}$. Malaga, die nächstgelegene Stadt auf spanischem Territorium, kam ins Visier ${ }^{303}$. Angesichts der im April zuvor beim Briten Charles Gardiner erfolgten Bestellung von Gasbomben ist nicht auszuschließen, daß Abdelkrim seinerseits über Gasangriffe aus der Luft nachdachte. Perrier erhielt den Auftrag, weitere Flugzeuge ins Rif zu fliegen. Am 2. Januar 1924 kehrten er und Caïd Haddou nach Algier zurück ${ }^{304}$.

Dort hatte sich die Lage mittlerweile völlig verändert. Das Generalgouvernement hatte Georges-Marie Haardt, Eugène Allard und Pierre Ghisolfi verdeutlicht, daß die offiziellen Stellen Algeriens weitere Verkäufe und Überführungen von Flugzeugen nicht dulden würden. Die restlichen Maschinen der S.R.A.T. wurden von Soldaten überwacht und eingezäunt, ihre Motoren wurden ausgebaut ${ }^{305}$. Paris entsandte in Richtung Algerien und an die französische Generalresidenz in Rabat klare Anweisungen, Hilfsmaßnahmen jeglicher Art für Abdelkrim zu unterlassen ${ }^{306}$.

Dieser jedoch gab nicht auf. Er erteilte Haddou den Auftrag, französische Piloten und Mechaniker anzuwerben, die in der Lage sein sollten, die erbeuteten spanischen Flugzeuge zu reparieren. Schon am 7. Januar 1924 schloß Haddou mit Raymond Perrier und Emest Millot, einem Flugzeugmechaniker aus Algier, Verträge ab. Capitaine Ducas und Pierre Ghisolfi hatten als Vermittler fungiert. Perrier sollte 7000 Francs pro Monat, Millot monatlich 6000 Francs verdienen. 10000 Francs sollten auf einer französischen Bank als Garantie für die Auszahlung des Monatslohns hinterlegt werden. Die alarmierten algerischen Behörden ließen Perrier und Millot in Oran überwachen. Generalgouverneur Théodore Steeg sah jedoch keine rechtliche Handhabe, sie an der Abreise ins Rif zu hindern ${ }^{307}$.

So schaffte es Haddou im Februar 1924 mühelos, die beiden Franzosen heimlich ins Rif zu schleusen. Neben ihren technischen Aufgaben sollten Perrier und Millot ein Zentrum zur Einweisung von Piloten errichten und Luftbilder zur Anfertigung einer topographischen Karte des Rifs erstellen ${ }^{308}$. Ihnen zur Seite sollte einer der besten französischen Piloten des Ersten Weltkrieges

${ }_{303}^{302}$ ABDELKRIM, Memoiren, S. 103.

${ }^{303}$ PAYNE, Politics, S. 493, Anm. 7.

${ }^{304}$ SHAT 3H1559: Commissariat de la sûreté régionale Oujda, Renseignements, 30.12.1923; ADMAE Maroc 219, 22: Gouverneur général de l'Algérie an MAE, 3.1.1924.

${ }^{305}$ ADMAE Maroc 219, 66: Consul genéral de France Oujda an RG Rabat, 29.1.1924; ADMAE Maroc 219, 6: Gouverneur général de l'Algérie an MAE, 30.12.1923.

${ }^{306}$ ADMAE Maroc 219, 19: MAE an Gouverneur général de l'Algérie, 1.1.1924; ADMAE Maroc 219, 34: MAE an Gouverneur général de l'Algérie, 16.1.1924; ADMAE Maroc 219, 3: MAE an RG Rabat, 28.12.1923.

${ }^{307}$ ADMAE Maroc 219, 65: RG Rabat an MAE, 18.2.1924; ADMAE Maroc 219, 66: Consul général de France Oujda an RG Rabat, 29.1.1924; ADMAE Maroc 219, 50: Gouverneur général de l'Algérie an MAE, 4.2.1924; WARD PRICE, Extra-Special Correspondent, S. 172.

${ }^{308}$ SHAT 3H1 102: Territoire de Taza, Cercle de Guercif, SR, Feuille de renseignements, 26.2.1924; Roger-MATHIEU, Mémoires, S. 225; FonTAINE, L'étrange aventure, S. 102. 
stehen. Agenten Abdelkrims versuchten, Capitaine René Fonck - zu dieser Zeit Parlamentsabgeordneter von Marseille - für die Organisation der RifLuftwaffe und für die Leitung von Luftoperationen gegen spanische Truppen zu gewinnen. Fonck lehnte aber $a b$ und erstattete der französischen Regierung Bericht $^{309}$.

Zwölf Kilometer westlich von Ajdir lag Izemouren, ein Dorf im Gebiet der Beqqioua. Dort wurde die einzige Landebahn des Rifs errichtet ${ }^{310}$. Der in Tanger lebende Brite John Arnall war einer der wenigen, der sie zu Gesicht bekam. Das Flugfeld lag auf einem Plateau, von dem aus bei guter Sicht die Straße von Gibraltar zu erkennen war. Vier Kanonen sollten spanische Schiffe hindern, sich der Küste zu nähern. Leichtere Geschütze dienten dem Schutz des Flugplatzes für Angriffe aus der Luft. In provisorischen Hangars standen vier defekte Flugzeuge sowie die von Perrier eingeflogene Maschine ${ }^{311}$. Es gab zwei Flugschüler von den Beni Ouriaghel und einen von den Beqqioua sowie drei europäische Ausbilder. Hierbei handelte es sich um Perrier, Millot und um einen Italiener namens Greco, den John Arnall im Januar 1924 für die Rifarmee engagiert hatte ${ }^{312}$.

Aber war diese Pilotentruppe wirklich aktiv? Abdelkrim widersprach sich selbst, indem er einmal sagte, daß kein Flugzeug jemals wieder aufgestiegen $\mathrm{se}^{313}$, an anderer Stelle jedoch vermerkte, eines habe die französischen Linien überflogen ${ }^{314}$. Tatsächlich wurde das Rifflugzeug von Perrier im Frühjahr 1924 beim Überfliegen des Marnissa-Gebietes gesichtet ${ }^{315}$. Marschall Lyautey

${ }^{309}$ The Riff Air Force. Captain Fonck Reveals an Offer from Abdel Krim, in: Manchester Guardian, 23.7.1925; Abd-el-Krim Wanted René Fonck to Organize Air Force, in: New York Times, 23.7.1925. Zu René Foncks Weltkriegseinsätzen: Paul-Louis WELLER, René Fonck, in: Revue des deux mondes 153 (1983) S. 533-540.

${ }^{310}$ GABRIELLI, Abd-el-Krim, S. 50.

${ }^{311}$ PRO-FO 174, 303, 76: Colonel Cummings, Military Headquarters Gibraltar an Allchin, General Consulate Tangier, 12.3.1924 mit den beigefügten Briefen John Arnall an Colonel Cummings, 10.2.1924 und 27.2.1924; PRO-FO 174, 303, 76: CG Tangier an FO, 7.3.1924; SHAT 3H1102: Territoire de Taza, Cercle de Guercif, SR, Feuille de renseignements, 23.1.1924; SHAT 3H1558: Bericht »Répertoire des organisations riffaines relevées au 10 décembre 1924 sur le front nord du territoire de Tazau, 10.12.1924; LE GUILLERME, CH. $) 402 \ll$, S. 164.

${ }^{312}$ SHAT 3H102: EMA, $2^{e}$ bureau, Bericht "Les italiens au Maroc", 24.1.1924; SHAT 3H135: EMA, Section d'Afrique, Renseignements, 7.2.1924; SHAT 3H1103: Contrôle civil de Taourirt, Bulletin de renseignements, 5.4.1924; FONTAINE, L'étrange aventure, S. 102.

313 ABDELKRIM, Memoiren, S. 103. Vgl. GABRIELLl, Abd-el-Krim, S. 50; FuRNEAUX, Abdel Krim, S. 91; WOOLMAN, Rebels in the Rif, S. 152; LOZE, L'etat-major, 14.4.1926; SHEEAN, Riffis Fight, 12.2.1925.

${ }^{314}$ DUMAS, Abd-el-Krim, S. 30.

${ }^{315}$ SHAT 3H1 103: Contrôle civil de Taourirt, Bulletin de renseignements, 5.4.1924; GODED LLOPIS, Marruecos, S. 102. 
berichtete zudem, Greco habe mehrmals die spanischen Linien überflogen ${ }^{316}$. Eine Rifmaschine warf im Frühjahr 1925 Desertionspropaganda über französischen Truppen $\mathrm{ab}^{317}$. Eine wirkliche militärische Rolle spielten die Flugzeuge also nicht.

Abdelkrims Traum von einer eigenen Luftwaffe platzte, als die besorgten Spanier zuschlugen. Am 23. März 1924 griffen insgesamt 52 Flugzeuge den Rif-Flugplatz an. 540 über Izemouren abgeworfene Bomben richteten schwere Verwüstungen an. Auch Abdelkrims einziges flugfähiges Flugzeug, die Bréguet aus Algerien, war irreparabel getroffen worden ${ }^{318}$. Raymond Perrier und Ernest Millot sahen ihr Werk durch die spanische Luftwaffe zerstört und kehrten im Juni 1924 nach Algerien zurück. Thre Forderung, das ausstehende Restgehalt von 20000 Francs ausgezahlt zu bekommen, lehnten Si Mohammed Azerkane und Si Mohammed Boujibar $a^{319}$. Dies mag der Grund dafür gewesen sein, daß Perrier den Spaniern präsentierte, was er über das Rif gesammelt hatte. Fotos zeigten Karawanenwege, Nachschubpfade, Abdelkrims Hauptquartier und Truppenbewegungen. Perrier verriet alles, was er wußte, und erhielt als Gegenleistung 1500 Peseten $^{320}$.

Als der englische Journalist George Ward Price im April 1924 das Rif besuchte, konnte er die fluguntüchtigen Maschinen in Augenschein nehmen. Es wurden Reparaturarbeiten vorgenommen, obwohl es ein aussichtsloses Unterfangen war $^{321}$. Auch deutsche Deserteure versuchten später mit wenig Erfolg, die vorhandenen Maschinen im Rif, die sich in einem sehr schlechten Zustand befanden, in Bouham zu reparieren. Es handelte sich unter anderem um Franz Koberstein und Hans Kempken ${ }^{322}$.

${ }^{316}$ SHAT 3H1558: Louis-Hubert Lyautey an Commandant de la région de Fès, 11.7.1924.

${ }^{317}$ ADMAE Maroc 220, 66: EMA, $2^{\mathrm{e}}$ bureau, Bericht »Propagande allemande au Maroc«, 20.5.1925.

${ }^{318}$ Payne, Politics, S. 493, Anm. 7; Fleming, Primo de Rivera and Abd-el-Krim, S. 225; Goded LlopIS, Marruecos, S. 102; FuRnEauX, Abdel Krim, S. 91; SANCHEZ, PereZ, Abdelkrim, S. 153; ADMAE Maroc 219, 80: Ambassade de Madrid an MAE, 27.3.1924.

${ }^{319}$ FONTAINE, L'étrange aventure, S. 102-105; KHARCHICH, La France, S. 111.

${ }^{320}$ SHAT 3H146: Consulado de Oujda an Alto Comisario de Tetuan, 9.9.1924.

${ }^{321}$ SHAT 3H102: MAE an MG, EMA, Section d'Afrique, 8.5.1924.

${ }^{322}$ CADN Maroc DAI 192: Tabor de police $\mathrm{N}^{\circ} 1$ Tanger an DAI Rabat, 11.7.1925 mit Bezug auf eine Befragung des deutschen Deserteurs Karl Millfahrt; SHAT 3H443: Bericht "Compte rendu d'interrogatoire du tirailleur Killif«, 20.11.1925; CADN Tanger C37: Tabor de police $\mathrm{N}^{\circ}$ 1, Bericht "Renseignements de source espagnole«, 18.12.1925; SHAT 3H1561: Bericht »Interrogatoire de Mouloud Ben Belaïd«, 4.6.1926; ADMAE Maroc 138, 82: Bericht »Interrogatoire de Haïmou Tayeb«, 7.6.1926; SHAT 3H442: Bericht »Déclarations du soldat Florio Louis«, 8.6.1926; SHAT 3H442: Bericht »Renseignements sur les trois légionnaires suspects« o.D. [Mitte 1926]. 
Abdelkrim versuchte weiter, über seine britischen Kontakte an Flugzeuge zu gelangen. Die englische Gesellschaft Supermarine lehnte im Oktober 1924 den Verkauf von Wasserflugzeugen $a b^{323}$. Der Brite Mathews aus Oxford hatte im Sommer 1924 seinen Geschäftspartner Charles Gardiner auf einer Fahrt ins Rif begleitet. Ende 1924 bemühte sich Mathews, zusammen mit Thomas Israel Perrott Flugzeuge für Abdelkrim zu erwerben. Aus Geldmangel ließ Mathews sein Projekt fallen ${ }^{324}$.

Im Juni 1927 berichtete »Times«-Korrespondent Walter B. Harris von zwei »fremden Offizieren«, die Abdelkrim über seine Mittelsleute in Tanger noch vor Ausbruch der Feindseligkeiten gegen Französisch-Marokko - also Anfang 1925 - ihre Hilfe angeboten hätten. Sie hätten vorgeschlagen, gegen die Bezahlung von 500000 Peseten ein spanisches Flugzeug mit Bewaffnung zu entwenden und damit Melilla oder Ceuta zu bombardieren. Die Vereinbarung sei nicht zustande gekommen, weil sie im voraus bezahlt werden wollten ${ }^{325}$.

Wer diese "fremden Offiziere« waren, ließ Harris offen. Allerdings hielt sich zu dieser Zeit bereits seit Monaten ein britischer Pilot namens Captain T.W.H. Sarrl in Tanger auf. Sarrl besaß in der Londoner Welton Street ein Geschäft, in dem auch Schmuckartikel aus dem Rif zu kaufen waren ${ }^{326}$. Am 31. August 1924 war Sarrl in Tanger angekommen. Er gab sich als Kriegsberichterstatter für die "Daily News« und die »United Cables of America« aus. Gegenüber dem britischen Generalkonsul drückte er klar seine Sympathie für die Sache Abdelkrims aus ${ }^{327}$. Gelegentlich traf sich Sarrl mit Abdelkrims britischen Sympathisanten in Tanger, mit Captain Mundey, mit der Familie Moxon - Nachfolger John Arnalls als Tangerer Repräsentanten der Bergbaufirma von James Fordham - sowie mit Gertrude Arnall ${ }^{328}$. Auch mit Robert GordonCanning und Gerald Spencer Pryse, die Ende Oktober 1924 in humanitärer Mission ins Rif aufbrachen, stand der Brite in Verbindung ${ }^{329}$.

${ }^{323}$ CADN Maroc DAI 194: Bericht »Note au sujet du ravitaillement en armes et munitions du Rif par mer«, 30.5.1925.

${ }^{324}$ PRO-FO 371, 10583: Embajada de Londres an FO, 12.8.1924; PRO-FO 371, 11080, 3: Embajada de Londres an FO, 31.12.1924; PRO-FO 371, 10582, 101, 141: Embassy of Madrid an FO, 12.11.192; PRO-HO 45, 12067, 476042, 14: HO an FO, 21.4.1925.

${ }^{325}$ HaRRIS, Tangier Problem, 4.6.1927.

${ }^{326}$ AN F7, 14980: Bureau franco-espagnol Malaga, Note, 20.5.1925.

${ }^{327}$ PRO-FO 371, 10582, 101, 141: Embassy of Madrid an FO, 12.11.1924; PRO-FO 371, 12687, 11, 184: Ambassade de Londres an FO, 21.2.1927.

${ }^{328}$ SHAT 3H102: EMA, $2^{\circ}$ bureau, Bericht $w$ Renseignement du capitaine aviateur anglais Sarrl«, 3.3.1926; PRO-FO 371, 12687, 11, 190: Ambassade de Londres an FO, 25.2.1927; TERRIER, Les "Frères de la côte« 1926, S. 43, Anm. 3.

${ }^{329}$ PRO-FO 371, 11079, 39, 70: New Scotland Yard an FO, 10.8.1925. 
Im Februar 1925 verließ Captain Sarrl Tanger. Am 16. März 1925 gelangte er in einheimischer Kleidung von Taourirt aus ins $\mathrm{Rif}^{330}$. Hierbei wurde er von Robert Rollo Leclercq Rivett-Carnac alias Harry Radleigh, der im Rif "Löwe der Sahara genannt wurde, begleitet. Beide kannten sich seit 1906 aus gemeinsamen Zeiten in Südafrika ${ }^{331}$. Sie boten Abdelkrim an, 200 Bomberflugzeuge zu beschaffen, verlangten jedoch einen zu hohen Preis ${ }^{332}$. Den Auftrag, Ersatzteile für die Reparatur von Flugzeugen zu organisieren sowie Piloten und Ingenieure anzuwerben, konnte Sarrl nicht erfüllen ${ }^{333}$.

Abdelkrims Drohung im Sommer 1925, Spanien und Frankreich aus der Luft anzugreifen, verpuffte daher ins Leere, denn es fehlte an Equipment und Experten $^{34}$. Der amerikanische Journalist Larry Rue berichtete zur gleichen Zeit, daß die Rifkabylen drei erbeutete Flugzeuge vom Flugplatz Mediouna verbrennen mußten, weil sie sie nicht verwenden konnten ${ }^{335}$.

Im Juni 1925 gab es Berichte, daß mit einem Schiff der Oldenburgisch-Portugiesischen Dampfschiffahrtsgesellschaft (OPDG) ein zerlegtes Fokker-Flugzeug nach Marokko transportiert werden sollte ${ }^{336}$. Tatsächlich wurde der holländische Honorarkonsul in Larache, der zu dieser Zeit auch die Funktion des Konsuls von Tanger wahrnahm, darauf angesprochen, ob er die Anlieferung zerlegter Flugzeuge an Abdelkrim weitervermitteln könne. Er lehnte allerdings $\mathrm{ab}^{337}$.

Robert Gordon-Canning, der Brite Lt.-Colonel Arthur John Barry und Karl Hackländer waren in diese Affäre verwickelt. Hackländers und Gardiners Wege hatten sich mittlerweile aus unbekannten Gründen getrennt ${ }^{338}$. Zusammen mit Gordon-Canning entwickelte der Deutsche die Idee, ein Flugzeug der Firma Fokker ins Rif zu entsenden. Gordon-Cannings ursprünglicher Gedanke, daß ein vom »Daily Express« engagierter Pilot mit einer Maschine direkt Chi-

${ }^{330}$ SHAT 3H102: EMA, $2{ }^{\mathrm{e}}$ bureau, Bericht "Renseignement du capitaine aviateur anglais Sarrk, 3.3.1926; Captain Sarrl, in: Al-Moghreb al Aksa \& Tangier Gazette, 20.6.1925.

${ }^{331}$ PRO-FO 371, 11920, 3715, 105: HO an FO, 10.6.1926 mit einem beigefügten Bericht der Metropolitan Police, 30.5.1926; PRO-FO 371, 11920, 104: Minute, 12.6.1926; A General of the Riffi, in: Cornhill Magazine 60 (1926) S. 558-563.

${ }_{332}^{32}$ AN 313 AP 247: Tabor de police $\mathrm{N}^{\circ}$ 1, Note, 7.5.1925.

${ }^{333}$ CADN Tanger C38: CG Tanger an RG Rabat, 6.7.1925; PRO-FO 371, 11079, 39, 70 : New Scotland Yard an FO, 10.8.1925; CADN Tanger C39: Tabor de police $N^{\circ} 1$, Bulletin de renseignements, 9.11.1925 und 14.11.1925; PRO-FO 371, 12687, 11, 190: Ambassade de Londres an FO, 25.2.1927.CADN Tanger C40: Tabor de police $\mathrm{N}^{\circ} 1$, Bulletin de renseignements, 8.1.1926; CADN Tanger C38: CG Tanger an RG Rabat, 4.2.1926; CADN Tanger C38: CG Tanger an RG Rabat, 19.2.1926.

${ }^{334}$ L'agression des Rifains contre le Maroc français, in: BCAF 35 (1925) S. 362.

${ }^{335}$ RUE, Riff Warriors, 25.6.1925.

${ }^{336}$ ADMAE Maroc 220, 122: Bericht "Avions pour le Riffu, 23.6.1925; Abd-el-Krim's Aeroplanes, in: Times, 4.8.1925.

${ }^{337}$ CADN Tanger C38: Gouverneur général de l'Algérie, Renseignement, 4.2.1926.

${ }^{338}$ Walter B. HARRIS, Captain Canning and Abd-el-Krim, in: Times, 30.1.1926. 
chaouen anfliegen sollte, wurde verworfen. Zwei andere Flugzeuge sollten, so schlug Hackländer am 15. August 1925 vor, unter dem Banner des Britischen Roten Kreuzes oder Halbmondes von Lissabon aus das Rif anfliegen. Er hoffte, weitere Angebote von Nordflug, Junkers und Dornier zu erhalten. Zudem plante Hackländer, den besten Mechaniker seiner Wermelskirchener Firma für die Wartung der Motoren mitzunehmen. Er sei sicher, schrieb er Gordon-Canning, daß Abdelkrim nach einer ersten Probelieferung sofort über moderne Flugzeuge für den »Inlandsverkehr« sowie für seine persönliche Umgebung und seinen Generalstab verfügen wolle ${ }^{339}$. Abdelkrim zufolge sollten die Maschinen als Sanitätsflugzeuge eingesetzt werden ${ }^{340}$. Bei Dar Akoba in der Nähe Chichaouens wurde unter der Leitung von neun Europäern ein weiteres Flugfeld vorbereitet ${ }^{341}$. Hackländers Plan wurde aber aus unbekannten Gründen nicht verwirklicht.

Nachdem der Rechtsrat der italienischen Gesandtschaft in Tanger Naldo Malmusi dem Rif im April 1925 einen Besuch abgestattet hatte ${ }^{342}$, verfügte Abdelkrim über Kontakte nach Italien. Am 16. September 1925 erreichte der Italiener Mario Magri in Begleitung des Journalisten Alfredo Morea das Rif. Magri stand in engem Kontakt zu Benito Mussolini und gab an, von der italienischen Regierung geschickt worden $\mathrm{zu} \mathrm{sein}^{343}$. Er schlug vor, aus dem geographisch günstig gelegenen Italien Ersatzteile für Abdelkrims Flugzeuge zu beschaffen ${ }^{344}$. Magris Aufenthalt erregte im Rif Verdacht. Abdelkrims Militärberater Josef Klems sagte einem französischen Informanten, daß er befürchte, die Khattabi-Brüder würden bei einer Niederlage nach Italien fliehen ${ }^{345}$. Es kursierten Gerüchte, daß ein italienischer Pilot Abdelkrim im Notfall aus dem Rif ausfliegen sollte ${ }^{346}$. Magri bot sich als Pilot für eine von ihm zu bildende

${ }^{339}$ ADMAE Maroc 133, 11: Karl Hackländer an Robert Gordon-Canning, 15.8.1925; CADN Maroc DAI 189: Bericht »Renseignements fournis par le Caïd Haddou«, 28.6.1926; KHARCHICH, La France, S. 162f. u. S. 162, Anm. 3; Jacques LADRET DE LACHARRIERE, Les origines et les conséquences du soulèvement rifain, in: Revue hebdomadaire 34 (1925) S. 223237, S. 235; SICARD, Doriot, S. 145.

${ }_{340}$ ROGER-MATHIEU, Mémoires, S. 170.

${ }^{341}$ CADN Tanger C37: Région de Fès, SR, Bulletin de renseignements, 20.7.1925; Les rifains organiseraient un corps d'aviation, in: Matin, 11.7.1925.

${ }^{342}$ Siehe auch Kapitel 6, S. 273.

${ }^{343}$ CADN Rome 453: MAE an Ambassade de Rome, 19.10.1925; ADMAE Maroc 133, 195 : MI, Sûreté générale an MAE, 10.2.1926; CADN Tanger C40: Tabor de police $\mathrm{N}^{\circ}$ 1, Bericht »Renseignements donnés par Abdelkrim El Hadj Ali El Bokkoyi«, 5.3.1926; SHEEAN, Personal History, S. 161.

${ }^{344}$ CADN Rome 453: MAE an Ambassade de Rome, 19.10.1925.

${ }^{345}$ ADMAE Maroc 135, 76: Tabor de police $\mathrm{N}^{\circ}$ 1, Bulletin de renseignements, 31.12.1925.

${ }^{346}$ Abdel Krim, in: Kölnische Zeitung, 7.1.1926; TERRIER, Les »Frères de la côte« 1926, S. 70 . 
Flugstaffel, die Melilla oder Fes bombardieren sollte, an. Als eine französische Bréguet im Gebiet der Branès abstürzte, eilte Magri mit Helfern dorthin, um das Flugzeug wieder funktionstüchtig zu machen. Doch Einheimische hatten den Piloten getötet und dessen Maschine völlig demoliert ${ }^{347}$.

Zusammen mit einer bei Chichaouen abgestürzten Goliath-Maschine besaß Abdelkrim nun fünf defekte Flugzeuge, aber es fehlte ihm weiter Ersatzmaterial, Benzin und Personal ${ }^{348}$. Magri schlug vor, in Italien vier Bomber und sechs Jagdflugzeuge zu kaufen ${ }^{349}$. Abdelkrim konnte oder wollte $z u$ diesem Zeitpunkt die von Magri für den Ankauf geforderten 300000 Peseten nicht mehr aufbringen. Der Italiener gab daher an zu versuchen, in Italien Geldgeber zu finden. Er verließ am 14. Januar 1926 Tamasint und kam zwei Wochen später in Tanger an. Die Rifkabylen hörten nie wieder etwas von ihm - vermutlich, weil ihre militärische Lage zu diesem Zeitpunkt bereits sehr prekär $\operatorname{war}^{350}$.

Abdelkrims Pläne einer eigenen Flugzeugstaffel mögen im Nachhinein utopisch erscheinen. Wie ernst sie aber gemeint waren, zeigt sich darin, daß es ihm tatsächlich gelang, Granaten und Flugzeug-Einzelteile ins Rif einzuschmuggeln. Spanische Truppen konfiszierten bei Kriegsende 1022 Bomben und 53 Kisten eines zerlegten französischen Flugzeugs. Niemand weiß, welche sonstigen Mengen an Waffen und Munition letztendlich ins Rif gelangten. Abdelkrims Truppen übergaben den Spaniern zusätzlich 128 Artilleriegeschütze mit 4549 Granaten, sieben Mörser, 232 Maschinengewehre und rund 1800 Handgranaten $^{351}$. Bis Ende 1926 sammelten die Spanier 58000 Gewehre ein ${ }^{352}$. Zwischen 1927 und 1930 wurden den Rifkabylen zudem 66269 Gewehre abgenommen ${ }^{353}$. Insgesamt betrachtet, läßt sich festhalten, daß die Nachschublieferungen ins Rif, auch wenn sie nur in Einzelfällen zu quantifizieren sind, eine internationale Dimension hatten, die zumindest als beachtlich einzuschätzen ist.

${ }^{347}$ CADN Maroc DAI 189: Bericht »Renseignements fournis par le Caïd Haddou«, 28.6.1926; SHEEAN, Personal History, S. 150.

${ }^{348}$ CADN Tanger C40: Tabor de police $N^{\circ}$ 1, Information, 3.2.1926 mit Bezug auf Aussagen von Mario Magri; SHAT 3H102: RG Rabat an MG, EMA, $2^{\complement}$ bureau, 13.2.1926; DUMAS, Abd-el-Krim, S. 29.

${ }^{349}$ CADN Tanger C39: Tabor de police $\mathrm{N}^{\circ} 1$, Bericht »Extrait de l'interrogatoire de Reuter, Josef«, 21.11.1925; SHAT 3H102: EMA, $2^{\mathrm{e}}$ bureau, Renseignement, 27.11.1925.

${ }^{350}$ SHAT 3H102: RG Rabat an MG, EMA, $2^{\circ}$ bureau, 13.2.1926; CADN Tanger C40: Tabor de police $\mathrm{N}^{\circ}$ 1, Renseignements, 27.2.1926; ADMAE Maroc 133, 195: MI, Sûreté générale an MAE, 10.2.1926; CADN Maroc DAI 189: Bericht »Renseignements fournis par le Caïd Haddou《, 28.6.1926.

${ }^{351}$ ESPAÑA, La actuación, S. 364.

${ }^{352}$ WOOLMAN, Rebels in the Rif, S. 213.

${ }^{353}$ Shannon E. FLEMING, Spanish Morocco and the Second Republic. Consistency in Colonial Policy, in: Mediterranean Historical Review 13 (1998) S. 80-99, 80; DERS., Primo de Rivera and Abd-el-Krim, S. 226. 
